\title{
Evaluation of the Therapeutic Potential of the Novel Isotype Specific HDAC Inhibitor 4SC-202 in Urothelial Carcinoma Cell Lines
}

\author{
Maria Pinkerneil $^{1} \cdot$ Michèle J. Hoffmann $^{1} \cdot$ Hella Kohlhof ${ }^{2}$. \\ Wolfgang A. Schulz ${ }^{1}$ - Günter Niegisch ${ }^{1}$
}

Published online: 2 June 2016

(C) The Author(s) 2016. This article is published with open access at Springerlink.com

\begin{abstract}
Background Targeting of class I histone deacetylases (HDACs) exerts antineoplastic actions in various cancer types by modulation of transcription, upregulation of tumor suppressors, induction of cell cycle arrest, replication stress and promotion of apoptosis. Class I HDACs are often deregulated in urothelial cancer. 4SC-202, a novel oral benzamide type HDAC inhibitor (HDACi) specific for class I HDACs HDAC1, HDAC2 and HDAC3 and the histone demethylase LSD1, shows substantial anti-tumor activity in a broad range of cancer cell lines and xenograft tumor models.

Aim The aim of this study was to investigate the therapeutic potential of 4SC-202 in urothelial carcinoma (UC) cell lines. Methods We determined dose response curves of 4SC-202 by MTT assay in seven UC cell lines with distinct HDAC1, HDAC2 and HDAC3 expression profiles. Cellular effects were further analyzed in VM-CUB1 and UM-UC-3 cells by colony forming assay, caspase-3/7 assay, flow cytometry, senescence assay, LDH release assay, and immunofluorescence staining. Response markers were followed by quantitative real-time PCR and western blotting. Treatment with the class I HDAC specific inhibitor SAHA (vorinostat) served as a general control.
\end{abstract}

Electronic supplementary material The online version of this article (doi:10.1007/s11523-016-0444-7) contains supplementary material, which is available to authorized users.

Günter Niegisch

guenter.niegisch@hhu.de

1 Department of Urology, Medical Faculty, Heinrich-Heine-University, Moorenstr. 5, 40225 Duesseldorf, Germany

2 4SC AG, Martinsried, Germany
Results 4SC-202 significantly reduced proliferation of all epithelial and mesenchymal UC cell lines ( $\mathrm{IC}_{50} 0.15-0.51 \mu \mathrm{M}$ ), inhibited clonogenic growth and induced caspase activity. Flow cytometry revealed increased $\mathrm{G} 2 / \mathrm{M}$ and subG1 fractions in VM-CUB1 and UM-UC-3 cells. Both effects were stronger than with SAHA treatment.

Conclusion Specific pharmacological inhibition of class I HDACs by 4SC-202 impairs UC cell viability, inducing cell cycle disturbances and cell death. Combined inhibition of HDAC1, HDAC2 and HDAC3 seems to be a promising treatment strategy for UC.

\section{KeyPoints}

4SC-202 exerts significant antineoplastic effects on urothelial carcinoma (UC) cells.

4SC-202 induces strong mitotic disturbances in UC cells.

The 4SC-202 mediated effects are characterised by combined induction of apoptotic and necrotic cell death.

\section{Introduction}

The efficacy of systemic treatment in patients suffering from metastatic urothelial carcinoma (UC) is limited. Although about half of the patients respond initially to platinum-based polychemotherapy, up to $90 \%$ of patients will present with tumor relapse within less than 5 years [1-3]. Following the successful integration of "targeted therapeutics", which inhibits distinct cancer pathways, e.g. MAP kinase or PIK3 kinase/Akt signaling, into modern oncological treatment, 
according approaches have also been tested in UC [4-6]. However, up to now, none of these attempts has been successful $[7,8]$. Inefficacy of targeted therapeutics may be due to various resistance mechanisms by which UC cells circumvent drug-induced inactivation of essential signaling pathways [9].

As cancer pathways generally ultimately exert their effects by regulating gene expression, a more promising treatment strategy might consist of targeting gene expression more directly. This could be achieved, among others, by inhibition of histone deacetylases (HDACs). The HDAC family consists of 18 isoenzymes classified into so-called "classical" HDACs (HDAC1-11; class I, class II and class IV) and sirtuins (Sirt1-7; class III) [10-12]. Especially, class I HDACs (HDAC1, HDAC2, HDAC3, and HDAC8) act as transcriptional repressors and their expression profiles are prognostic in several malignancies [13-17]. HDAC inhibitors (HDACi) exhibit therapeutic efficacy in some hematological and solid cancers, and several isoenzymeunspecific HDACi (pan-HDACi) are approved for the treatment of specific hematological malignancies [18, 19]. In UC cell lines, pan-HDACi are also active by inducing apoptosis and cell cycle arrest [20, 21]. However, the observed preclinical effects of panHDACi are limited overall, perhaps because effects on different isoenzymes counterbalance each other.

Isoenzyme-specific inhibition of distinct HDACs might be more efficient. For example, selective inhibition of HDAC8 inhibited cell proliferation and clonogenic growth in a preclinical neuroblastoma cell culture model and, albeit less efficiently, in urothelial cancer cell lines $[22,23]$. In a recent analysis on selective inhibition of class I HDACs, simultaneous and selective inhibition of the class I HDACs HDAC1 and HDAC2 resulted in significant decreases of cell viability, proliferation and clonogenicity associated with accumulation of cells in the $\mathrm{G} 2 / \mathrm{M}$ cell cycle phase [24].

4SC-202 is a novel isotype-specific HDAC inhibitor that also inhibits KDM1A/LSD1 (Lysine (K)-specific demethylase 1A). It has been tested in a phase I trial (TOPAS) for the treatment of advanced hematological malignancies [25]. 4SC-202 is a benzamide type inhibitor with strong activity against HDAC1 $\left(\mathrm{IC}_{50}: 0.16 \mu \mathrm{M}\right), \operatorname{HDAC} 2(0.37 \mu \mathrm{M})$ and HDAC3 $(0.13 \mu \mathrm{M})$, without affecting other HDAC enzymes at clinically relevant concentrations $\left(\mathrm{IC}_{50}\right.$ : HDAC4, HDAC5, HDAC6, HDAC 7, HDAC 8, HDAC 9, HDAC 10 , HDAC11 $>15 \mu \mathrm{M}$ ) (updated, unpublished data, personal communication by H.K., detailed data available upon request). The reported $\mathrm{IC}_{50}$ for $\mathrm{KDM} 1 \mathrm{~A} / \mathrm{LSD} 1$ ranges in clinically relevant concentrations from 0.6 to $1.2 \mu \mathrm{M}$ (Data presented at Sixth Annual EpiCongress, Boston, USA, July 2015, data available online at https://4SC.de).

In this context, we evaluated the efficacy of 4SC-202 in UC cells. To our knowledge, this is the first detailed preclinical characterization of the novel isotype-specific HDAC inhibitor 4SC-202 in UC.

\section{Material and Methods}

\subsection{Cell Culture and Treatment}

Experiments were performed in the urothelial cancer cell lines (UCCs) VM-CUB1, RT-112, SW-1710, 639-V, UM-UC-3, 5637 and T-24 (provided by Dr. M. A. Knowles, Leeds, UK; Dr. J. Fogh, New York, USA; Dr. B. Grossmann, Houston, USA; DSMZ, Braunschweig, Germany) representing the heterogeneous phenotypes of urothelial carcinoma and different HDAC expression patterns [20, 24]. To investigate the tumor specificity of 4SC-202, experiments were further performed in two different urothelial control cell lines, HBLAK (spontaneously immortalized from primary human bladder epithelial cells, provided by CELLnTEC, Bern, Switzerland) and TERT-NHUC (TERT-immortalized normal human urothelial cells, provided by Dr. M. A. Knowles, Leeds, UK), and in the non-malignant, non-urothelial cell line HEK-293 (provided by Dr. V. Kolb-Bachofen, Duesseldorf, Germany) as previously described [24]. UCCs and HEK-293 cells were cultured in DMEM GlutaMAX-I (Gibco, Life Technologies, Darmstadt, Germany) supplemented with $10 \%$ fetal calf serum (Biochrom, Berlin, Germany) at $37{ }^{\circ} \mathrm{C}$ and $5 \% \mathrm{CO}_{2}$. HBLAK cells were cultured in CnT-Prime Epithelial Culture Medium (CELLnTEC, Bern, Switzerland). TERT-NHUC cells were cultured in supplemented keratinocyte serum-free medium (KSFM, Gibco) [26]. KSFM-Medium was supplemented with $0.25 \mathrm{ng} / \mathrm{ml}$ EGF (epidermal growth factor; Gibco), $12.5 \mu \mathrm{g} / \mathrm{ml}$ BPE (bovine pituitary extract; Gibco) and $1 \%$ ITS (insulin transferrin selenium; Life Technologies, Darmstadt, Germany), $0.35 \mu \mathrm{g} / \mathrm{ml} \mathrm{N}$-epinephrine (Sigma Aldrich, St. Louis, MO) and $0.33 \mathrm{mg} / \mathrm{ml}$ hydrocortisone (Sigma Aldrich). Differentiation of HBLAK cells was performed after cells reached $90 \%$ confluence according to a published protocol [27]. Briefly, cells were treated with $2 \mathrm{mM} \mathrm{CaCl}_{2}$ and medium was supplemented with $5 \% \mathrm{FCS}$. Cells were maintained under these conditions for 7 days, while medium was changed every 3 days. Subsequently, cells were treated with $0.5 \mu \mathrm{M}, 2.5 \mu \mathrm{M} 4 \mathrm{SC}-202$ or DMSO as a control for $72 \mathrm{~h}$.

For all cell lines, short tandem repeat (STR) profiling was recently performed by standard DNA fingerprint analysis (analysis reports available upon request; supplemental Table S1 in Online Resource 1).

Inhibitor experiments were performed $24 \mathrm{~h}$ after cell seeding with a single dose of 4SC-202 (provided by 4SC AG, Martinsried, Germany), vorinostat $(2.5 \mu \mathrm{M}$, SAHA [suberoylanilide hydroxamic acid]; \#1009929, Cayman Chemicals, Ann Arbor, MI), romidepsin (3 nM, S3020, Selleck Chemicals, Munich, Germany), givinostat $(0.5 \mu \mathrm{M}$, S2170, Selleck Chemicals) or the LSD1 inhibitor (LSD1i) SP2509 (VM-CUB1: $0.75 \mu \mathrm{M}, \mathrm{UM}-U C-3: 0.5 \mu \mathrm{M}, \mathrm{S} 7680$, Selleck Chemicals). Throughout, the previous characterized 
pan-HDACi SAHA served as control HDACi [20, 24]. The previously characterized class I HDACi romidepsin (histone acetylation, morphology, class I HDAC expression after HDACi treatment) and givinostat (morphology) were used as additional controls or for comparison with 4SC-202 [24]. As a positive control in LDH (lactate dehydrogenase) measurements, cells were treated with bortezomib (50 nM, S1013, Selleck Chemicals) or actinomycin D (4 $\mathrm{g} / \mathrm{ml}$, A1410, Sigma Aldrich). For distinguishing modes of cell death, cells were treated additionally with Necrox-2 (20 $\mu \mathrm{M}$, sc-391057, Santa Cruz, Dallas, USA) or Q-VD-OPh (30 $\mu \mathrm{M}$, SML0063, Sigma Aldrich); Etoposide was used to induce apoptosis ( $25 \mu \mathrm{M}, \mathrm{S} 1225$, Selleck Chemicals) and $\mathrm{H}_{2} \mathrm{O}_{2}$ to induce necrosis (30 $\mu \mathrm{M}, 107210$, Merck, Darmstadt, Germany) as previously described [24]. As a positive control for histone acetylation analysis, VM-CUB1 cells were also treated with romidepsin (3 nM, S3020, Selleck Chemicals) [24]. Inhibitors were dissolved in DMSO (dimethyl sulfoxide) as a stock of $10 \mathrm{mM}$. Control cells were treated with DMSO only at a maximum of $0.1 \%$.

\subsection{Determination of Mean Inhibitory Concentrations ( $\left.\mathrm{IC}_{50}\right)$, Viability, Apoptosis Induction and LDH Assay}

The mean inhibitory concentrations $\left(\mathrm{IC}_{50}\right)$ and viability after $72 \mathrm{~h}$ treatment were measured by NAD(P)H-dependent 3-(4, 5-dimethylthiazol-2-yl)-2,5-diphenyltetrazolium bromide dye reduction assay (MTT, Thiazolyl blue formazan, M2128-G, Sigma Aldrich) as previously described [24]. For $\mathrm{IC}_{50}$ determination, UCCs and control cells were seeded into 96-well plates and treated in three independent experiments with a range of defined concentrations of the inhibitor. Cell viability was additionally measured by the CellTiter-Glo ${ }^{\circledR}$ assay (Promega, Mannheim, Germany). In brief, cells were treated with defined concentrations of HDACi or LSD1i, for 24 and $48 \mathrm{~h}$ in six-well plates and viability measurements were performed according to manufacturer's protocol following transfer of cell aliquots to 96-well plates. Apoptosis induction after 4SC-202 or SAHA treatment was quantified by the CaspaseGlo 3/7 assay (Promega) and normalized to cell viability measured by CellTiter-Glo® as previously described [24]. A necrosis assay measuring lactate dehydrogenase released from damaged cells was performed via the Pierce LDH Cytotoxicity Assay Kit (\#88954, Thermo Fisher Scientific, Rockford, USA).

\subsection{Colony Forming Assay and Giemsa-Staining}

Colony forming assays were performed after $24 \mathrm{~h}$ and $48 \mathrm{~h}$ HDAC or LSD1 inhibitor treatment. In detail, cells were plated in $6 \mathrm{~cm}$ plates at a density of 500-1500 cells per plate. Colonies formed after 2 weeks were washed with PBS (Biochrom,
Merck Millipore, Berlin, Germany), fixed in methanol and stained with Giemsa (Merck, Darmstadt, Germany).

\subsection{Flow Cytometry}

UCCs or control cells were cultured with 0.5 or $2.5 \mu \mathrm{M} 4 \mathrm{SC}$ 202, $2.5 \mu \mathrm{M}$ SAHA, $3 \mathrm{nM}$ romidepsin, 0.5 (UM-UC-3) or 0.75 (VM-CUB1) $\mu \mathrm{M}$ SP2509 (alone or in combination with romidepsin) or DMSO. Cell cycle analyses were performed after 24 and $48 \mathrm{~h}$ as previously described [24]. Attached cells and cells in the supernatant were stained with a PI-buffer containing $50 \mu \mathrm{g} / \mathrm{ml}$ propidium iodide, $0.1 \%$ sodium citrate and $0.1 \%$ Triton X-100 [28]. For assessing apoptotic cell death and necrosis, cells were incubated with Annexin V-FITC (fluorescein isothiocyanate, \#31490013X2, Immunotools, Friesoythe, Germany), PI (2 $\mu \mathrm{g} / \mathrm{ml}$ in PBS) and Annexin V binding buffer. Thereafter, flow cytometry was performed using a Milteny MACSQuant ${ }^{\circledR}$ Analyzer (Milteny Biotec $\mathrm{GmbH}$, Bergisch-Gladbach, Germany).

\subsection{Senescence Assay}

UCCs or control cells treated with 0.5 or $2.5 \mu \mathrm{M} 4 \mathrm{SC}-202$, $2.5 \mu \mathrm{M}$ SAHA or DMSO for 24 and $48 \mathrm{~h}$ were washed in PBS and fixed in $2 \%$ formaldehyde and $0.2 \%$ glutaraldehyde for $5 \mathrm{~min}$ at room temperature. After fixation, cells were washed twice in PBS before being stained overnight at $37{ }^{\circ} \mathrm{C}$ with fresh senescence associated $\beta-$ Gal staining solution $(1 \mathrm{mg} / \mathrm{ml}$ X-Gal (5-bromo-4-chloro-3-indolyl-beta-D-galacto-pyranoside; Merck, Darmstadt, Germany), $150 \mathrm{mM} \mathrm{NaCl}, 2 \mathrm{mM}$ $\left.\mathrm{MgCl}_{2}, 5 \mathrm{mM} \mathrm{K}_{3} \mathrm{Fe}(\mathrm{CN})_{6}, 5 \mathrm{mM} \mathrm{K} \mathrm{Fe}_{4}(\mathrm{CN})_{6}\right)$. Images were taken using the NIS-Elements software with a Nikon Eclipse TE2000-S microscope (Nikon, Tokyo, Japan).

\subsection{RNA Isolation, cDNA Synthesis and Quantitative Real-Time PCR}

RNA isolation, cDNA synthesis and quantitative real-time PCR were performed as previously described [23, 24]. In brief, total RNA from cultured cells was isolated by the Qiagen RNeasy Mini Kit (Qiagen, Hilden, Germany). Synthesis of cDNA was performed using QuantiTect Reverse Transcription Kit (Qiagen, Hilden, Germany) with an extended incubation time of $30 \mathrm{~min}$ at $42{ }^{\circ} \mathrm{C}$. QRT-PCR was performed using an ABI 7500 Fast PCR instrument (Life Technologies) with QuantiTect SYBR Green RT-PCR Kit (Qiagen, Hilden, Germany), QuantiTect Primer assays (Qiagen, Hilden, Germany) and self-designed primers, using the housekeeping gene TBP (TATA-box binding protein) as a reference (supplemental Table S2 in Online Resource 1). Technical duplicates had less than $10 \%$ standard deviation. 


\subsection{Western Blot Analysis}

Western blot analysis of whole-cell extracts was done as described previously [20, 24]. In brief, total protein was extracted for $30 \mathrm{~min}$ on ice by cell lysis in a RIPA-buffer (150 mM NaCl, $1 \%$ Triton X-100, $0.5 \%$ desoxycholate, $1 \%$ Nonidet P-40, $0.1 \%$ SDS, 1 mM EDTA, $50 \mathrm{mM}$ TRIS ( $\mathrm{pH} 7,6)$ containing a protease inhibitor cocktail (10 $\mu \mathrm{l} / \mathrm{ml}$, \#P-8340, Sigma-Aldrich). After determination of protein concentration by BCA protein assay (Thermo Scientific, Rockford, IL), lysates were separated in SDSpage gels and transferred to PVDF (polyvinylidene fluoride) membranes (Merck Millipore, Berlin, Germany). Membranes were blocked with $5 \%$ non-fat milk or BSA (bovine serum albumin) in TBST (150 mM NaCl, $10 \mathrm{mM}$ TRIS, pH 7.4 and $0.1 \%$ Tween-20), washed and then incubated with primary antibodies for $1 \mathrm{~h}$ at RT or overnight at $4{ }^{\circ} \mathrm{C}$. After washing, the membranes were incubated with horseradish peroxidase-conjugated secondary antibody at RT for $1 \mathrm{~h}$. Bands were visualized by SuperSignal ${ }^{\text {TM }}$ West Femto (Thermo Scientific, Rockford, IL) and WesternBright Quantum kit (Biozym, Hessisch Oldendorf, Germany). Alpha-tubulin or GAPDH were detected as loading controls. The antibodies used are listed in supplemental Table S3 in Online Resource 1.

\subsection{Purification and Analysis of Histones}

Histones were extracted following a published protocol using sulphuric acid extraction and TCA-precipitation [29]. One $\mu \mathrm{g}$ of each sample was used for western blot analysis with $15 \%$ SDS-PAGE gels and PVDF membranes (Merck Millipore, Berlin, Germany) as described above. Romidepsin (3 nM) treated VM-CUB1 cells served as positive controls for histone $\mathrm{H} 3$ and $\mathrm{H} 4$ acetylation. Used antibodies are listed in supplemental Table S3 in Online Resource 1.

\subsection{Immunofluorescence Stainings}

Nuclear morphology analysis and immunofluorescence stainings were performed on UCCs after treatment with the HDACi 4SC-202 (0.5 and 2.5 $\mu \mathrm{M})$, SAHA $(2.5 \mu \mathrm{M})$ or DMSO for 24 and $48 \mathrm{~h}$ as described before [24]. For nuclear morphology analysis, subsequent to fixation with $4 \%$ formaldehyde, cells were permeabilized with $0.5 \%$ Triton X100 in PBS for $10 \mathrm{~min}$ at RT. Blocking was performed in PBS buffer with $1 \% \mathrm{BSA}$ for $30 \mathrm{~min}$ at RT. The fixed and blocked cells were incubated for $1 \mathrm{~h}$ at RT with $14 \mathrm{nM}$ rhodamine phalloidin in blocking solution. Nuclei were stained with $1 \mu \mathrm{g} / \mathrm{ml}$ DAPI (4',6-diamidino-2phenylindole) for $3 \mathrm{~min}$ before mounting the cover slips
Table 1 4SC-202 mean inhibitory concentrations $\left(\mathrm{IC}_{50}\right)$

\begin{tabular}{ll}
\hline Cell line & $I C_{50}(S D)[\mu M]$ \\
\hline Urothelial cancer cell lines & \\
RT-112 & $0.40(0.04)$ \\
5637 & $0.15(0.02)$ \\
VM-CUB-1 & $\mathbf{0 . 3 8}(\mathbf{0 . 0 8})$ \\
SW-1710 & $0.47(0.03)$ \\
639-V & $0.38(0.05)$ \\
UM-UC-3 & $\mathbf{0 . 5 1}(\mathbf{0 . 1 1})$ \\
T24 & $0.36(0.04)$ \\
Control cell lines & \\
HBLAK & $\mathbf{0 . 3 8}(\mathbf{0 . 0 5})$ \\
HEK-293 & $\mathbf{0 . 2 0}(\mathbf{0 . 0 9})$ \\
TERT-NHUC & $0.27(0.08)$
\end{tabular}

After treatment of cells with 4SC-202 for $72 \mathrm{~h}$, MTT assay was performed to assess cell viability. The cell lines highlighted by bold letters were used to further functional experiments. $S D$ standard deviation

with fluorescence mounting medium (DAKO, Glostrup, Denmark). For $\gamma \mathrm{H} 2 \mathrm{~A} . \mathrm{X} / 53-\mathrm{BP} 1$, double staining blocking (10 \% goat serum (Dako), 0.3 M glycine, $0.1 \%$ Triton X100 in PBS) was performed for $1 \mathrm{~h}$ at RT. After incubation overnight at $4{ }^{\circ} \mathrm{C}$ with the primary antibodies pH2A.X (1:50, \#2577, Cell Signaling Technology, Danvers, MA) and 53-BP1 (1:100, clone BP18, 05-725, Merck Millipore), cells were washed and incubated for $1 \mathrm{~h}$ at RT with 1:500 diluted Alexa Fluor 488 Goat Anti-Rabbit IgG and 1:250 diluted

Fig. 1 Impact of specific pharmacological inhibition of class I HDAC isoenzymes with $4 \mathrm{SC}-202$ on UCCs and control cells. a UCCs and control cells were treated with increasing amounts of the class I HDAC specific inhibitor 4SC-202. The dose-response curves after $72 \mathrm{~h}$ 4SC-202 treatment are shown exemplarily for the UCCs VM-CUB1 and UM-UC3 and the non-urothelial control cells HBLAK and HEK-293. b Nearconfluent HBLAK cells were maintained in regular medium (untreated) or differentiated by a $\mathrm{Ca}^{2+/} \mathrm{FCS}$ protocol and then treated with the indicated concentrations of 4 SC-202. After, $72 \mathrm{~h}$ viability was measured by the MTT assay. The calculated significances refer to the medium control. Additional significances between the different treatments are shown by brackets. Phase-contrast images of undifferentiated and differentiated cells are shown with a $20 \times$ magnification. $\mathbf{c}$ Levels of acetylated $\alpha$ tubulin and histone $\mathrm{H} 3$ and $\mathrm{H} 4$ were quantified in VM-CUB1 and UMUC-3 cells after defined 4SC-202 treatment $(0.5 / 2.5 \mu \mathrm{M}, 24 / 48 \mathrm{~h})$. Treatment with $3 \mathrm{nM}$ romidepsin served as positive control for $\mathrm{H} 3$ and $\mathrm{H} 4$ acetylation; treatment with $2.5 \mu \mathrm{M}$ SAHA served as a positive control for acetylated $\alpha$-tubulin. DMSO was the solvent control. d Effects of 4SC-202 and SAHA treatment $(24 / 48 \mathrm{~h})$ on HDAC1, HDAC2, HDAC 3 and HDAC8 mRNAs in VM-CUB1 and UM-UC-3 cells are shown. The calculated significances refer to the DMSO solvent control. $a c$ acetylated, $F C S$ fetal calf serum 
TRITC-Goat Anti-Mouse IgG $(\mathrm{H}+\mathrm{L})$ Conjugate. Cells were counter-stained with $1 \mu \mathrm{g} / \mathrm{ml}$ DAPI (4',6diamidino-2-phenylindole) for $3 \mathrm{~min}$. Images were taken with a Nikon Eclipse 400 microscope.

\subsection{Statistical Analysis}

Significance between groups was assessed by Student's $t$-test. $p$-values of $<0.05$ were considered as significant whereas
A
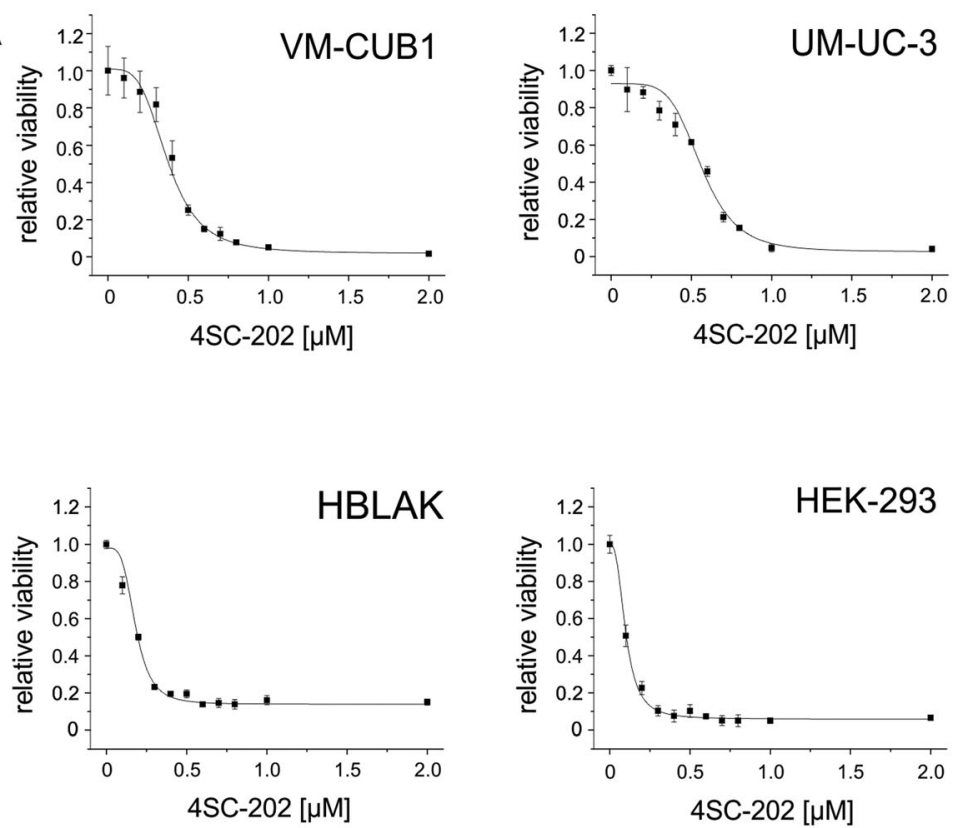

B

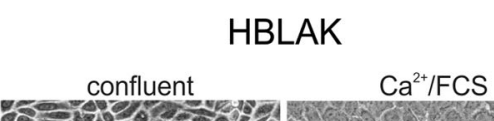

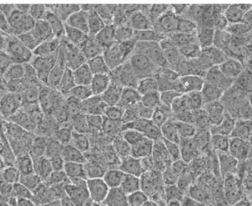

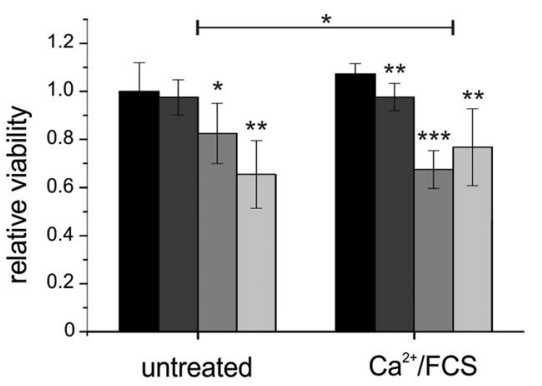

Medium DMSO

$0.5 \mu \mathrm{M} 4 \mathrm{SC}-202$

$2.5 \mu \mathrm{M} 4 \mathrm{SC}-202$

${ }^{*}=p<0.05^{* *}=p<0.01^{* * *}=p<0.001$

C

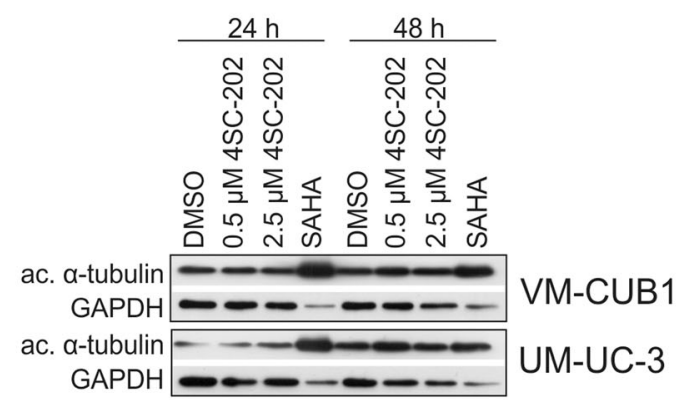

ac. $\alpha$-tubulin $55 \mathrm{kDa}$; GAPDH $36 \mathrm{kDa}$

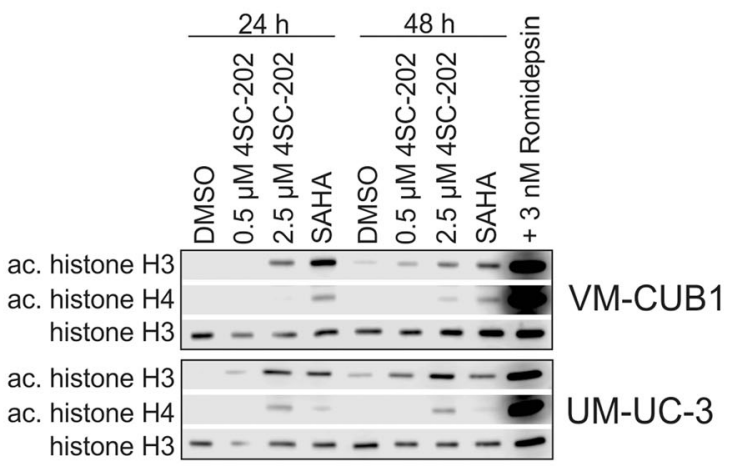

ac. histone H3 17 kDa; ac. histone H4 8 kDa; histone H3 17 kDa

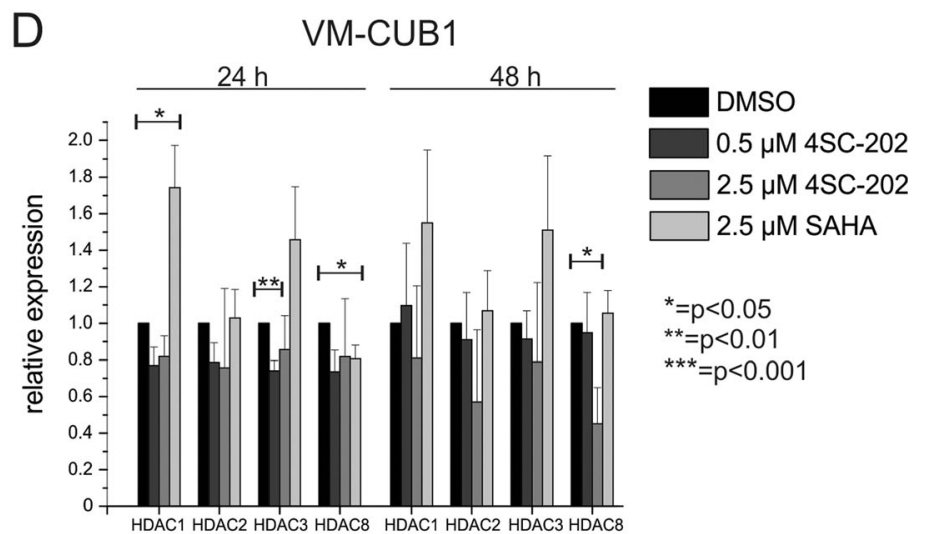

UM-UC-3

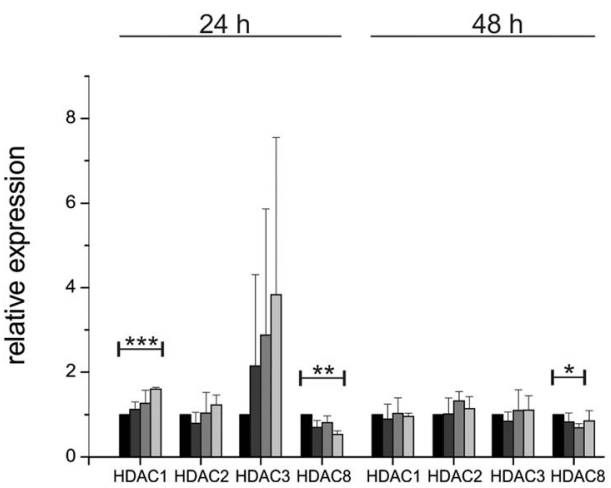


$p<0.01$ and $p<0.001$ were defined as highly significant. $\mathrm{IC}_{50}$ values and dose-response curves were approximated by nonlinear regression analysis using Origin 8.0 (Origin Lab, Northhampton, GB).

\section{Results}

\subsection{SC-202 Significantly Impacts Proliferation, Morphology and Clonogenicity of UC Cells}

First, we determined $\mathrm{IC}_{50}$ values of $4 \mathrm{SC}-202$ in seven UCCs (RT-112, VM-CUB1, SW-1710, 639-V, UM-UC-3, 5637, T-24), two urothelial (HBLAK, TERT-NHUC) and a nonurothelial (HEK-293) benign control. UCCs were chosen based on their HDAC expression profiles and morphological properties (epithelial-like vs. mesenchymal-like) as previously described $[20,24]$. Treatment with 4SC-202 resulted in a dose-dependent, significantly reduced proliferation rate of all UCCs, independent of their HDAC expression profile described elsewhere [20,24], with only slight variations in $\mathrm{IC}_{50}$ values (range: $0.15-0.51 \mu \mathrm{M}$ ). In HBLAK, TERTNHUC and HEK-293 cells, $\mathrm{IC}_{50}$ was $0.38,0.27$ and $0.20 \mu \mathrm{M}$, respectively (Table 1, Fig. 1a). To investigate how non-proliferative or differentiated HBLAK cells respond to 4SC-202 treatment, we assessed the effect of 4SC-202 on HBLAK cells in a confluent, growth-arrested or differentiated state induced by a $\mathrm{Ca}^{2+/}$ FCS differentiation protocol (Fig. 1b). Both growth-arrested and differentiated HBLAK cells were markedly less sensitive to 4SC-202, but with only slight differences between differentiated and undifferentiated cells.

More detailed experiments were then performed in representative epithelial-like (VM-CUB1) and mesenchymal-like (UMUC-3) UCC and in HBLAK and HEK-293 cells (Fig. 1a). As a pan-HDAC inhibitor control, all cell lines were likewise treated with SAHA, characterized previously by our group [20, 23, 24, $30]$. In the following experiments, the cells were treated generally with 0.5 and $2.5 \mu \mathrm{M} 4 \mathrm{SC}-202$ and $2.5 \mu \mathrm{M}$ SAHA (approximate $\mathrm{IC}_{50}$ in UCCs). In some experiments, treatments with $3 \mathrm{nM}$ romidepsin (histone acetylation, morphology, class I HDAC expression after HDACi treatment) or $0.5 \mu \mathrm{M}$ givinostat (morphology) were additionally investigated.

4SC-202 at $2.5 \mu \mathrm{M}$ and SAHA significantly enhanced the level of acetylated histone $\mathrm{H} 3$ in both UCCs. Acetylation changes of histone $\mathrm{H} 4$ (at 0.5 or $2.5 \mu \mathrm{M}$ 4SC-202) and of histone $\mathrm{H} 3$ (at $0.5 \mu \mathrm{M} 4 \mathrm{SC}-202$ ) were weaker and occurred mainly at later time points (Fig. 1c). Romidepsin $(3 \mathrm{nM})$ treated VM-CUB1 cells served as positive controls for histone $\mathrm{H} 3$ and $\mathrm{H} 4$ acetylation. Acetylation of $\alpha$-tubulin (depending mainly on HDAC6 activity) was not affected by $4 \mathrm{SC}-202$, whereas SAHA as a positive control induced strong $\alpha$-tubulin acetylation (Fig. 1c). The mRNA levels of class I HDACs were not consistently deregulated by 4SC-202 (Fig. 1d; Fig. S1 in Online Resource 2) with changes varying between the individual cell lines and without an evident relation to mesenchymal-like (639-V and T24) nor epithelial-like (RT-112 and 5637) phenotype.

To identify potential mechanisms involved in the inhibition of proliferation and clonogenicity in UCCs and control cells, we further investigated changes in cell morphology upon 4SC-202 or SAHA treatment (Fig. 2a). Additionally, morphology of cells treated with the specific HDAC1/2 inhibitors romidepsin $(3 \mathrm{nM})$ and givinostat $(0.5 \mu \mathrm{M})$ were compared. While only minor changes were observed upon SAHA treatment of UCCs, the number of detached, shrunk and blebbing cells suggestive of induction of apoptosis as well as the number of attached, enlarged and vacant-looking cells suggestive of senescent and/or necrotic cells were increased upon 4SC202 treatment. The morphology of UCCs following romidepsin and givinostat treatment is characterized by increased cell size and cell flattening. In contrast, $0.5 \mu \mathrm{M}$ 4SC-202 treated HBLAK cells assumed a senescence-like phenotype. The same changes were observed in HBLAK cells after givinostat and SAHA treatment, whereas romidepsin treated HBLAK cells became elongated with fibroblastoid morphology. Of note, treatment with the higher 4SC-202 concentration $(2.5 \mu \mathrm{M})$ induced rather an apoptotic phenotype in HBLAK cells (Fig. 2a). The non-urothelial non-malignant HEK-293 cells showed more pronounced morphological changes in cell attachment and shape, indicating apoptotic features following treatment with 4SC-202 than with romidepsin, givinostat or SAHA (Fig. 2a). Clonogenicity was impaired by treatment with either 4SC-202 or SAHA in VM-CUB1 and UM-UC-3 cells (Fig. 2b). Compared to SAHA, the effect of 4SC-202 on clonogenic growth was more durable, resulting in persistent inhibition even $48 \mathrm{~h}$ after treatment. In HEK-293 cells, clonogenicity was also more strongly inhibited by 4 SC-202 treatment (Fig. 2b).

To further determine whether treatment with 4SC-202 results in cell senescence, SA- $\beta$-Gal staining was performed. As shown in Fig. 2c, neither 4SC-202 nor SAHA significantly increased the fraction of senescent cells in UM-UC-3 and VM-CUB 1 cells. An increased fraction of SA- $\beta$-Gal positive cells was instead observed in non-urothelial HEK-293 cells and especially in the urothelial HBLAK controls (Fig. 2c).

\subsection{SC-202 Targets UC Cells by Induction of Apoptosis and Necrosis}

Further, we investigated to which extent apoptosis and necrosis contributed to cell death upon treatment with 4SC-202, as compared to SAHA (Fig. 3, supplemental Fig. S2 in Online Resource 2). For the evaluation of an apoptotic response, caspase- $3 / 7$ activity was measured after 24 and $48 \mathrm{~h}$ treatments with 4SC-202 or SAHA in UCCs and control cells (Fig. 3a). A 
A
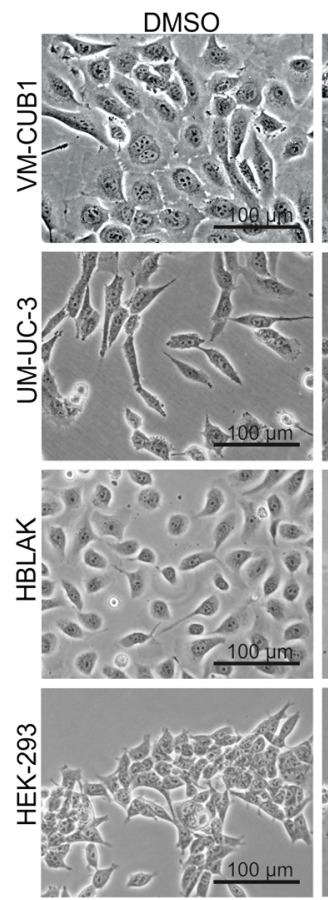
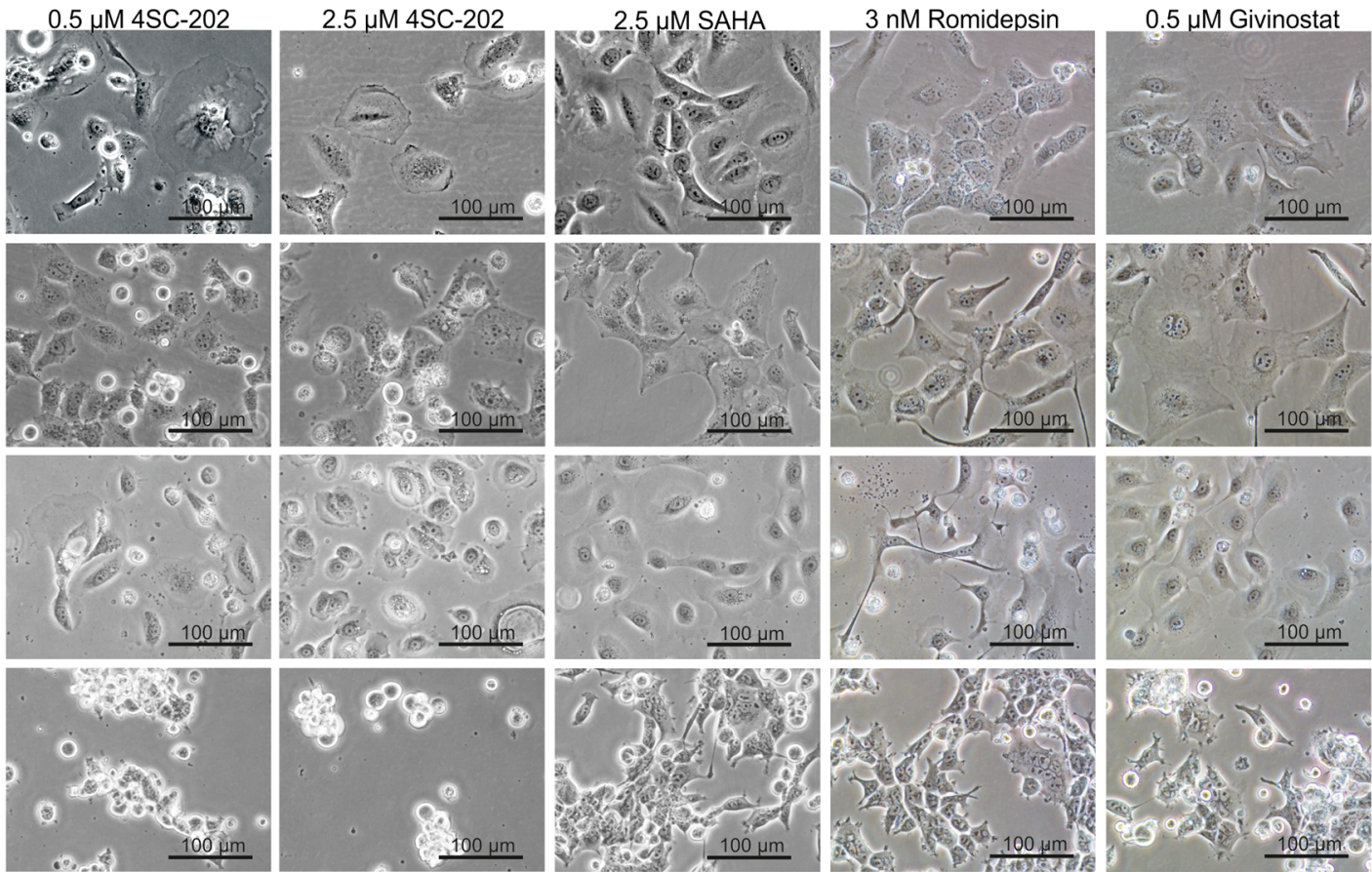

B

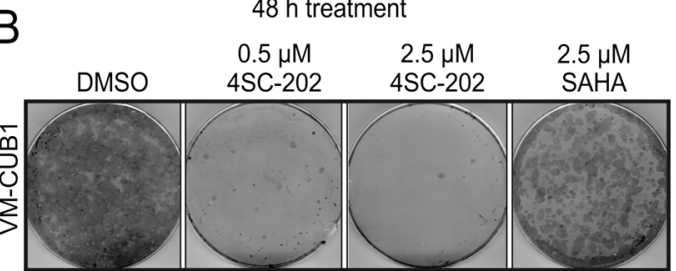

C

$48 \mathrm{~h}$ treatment
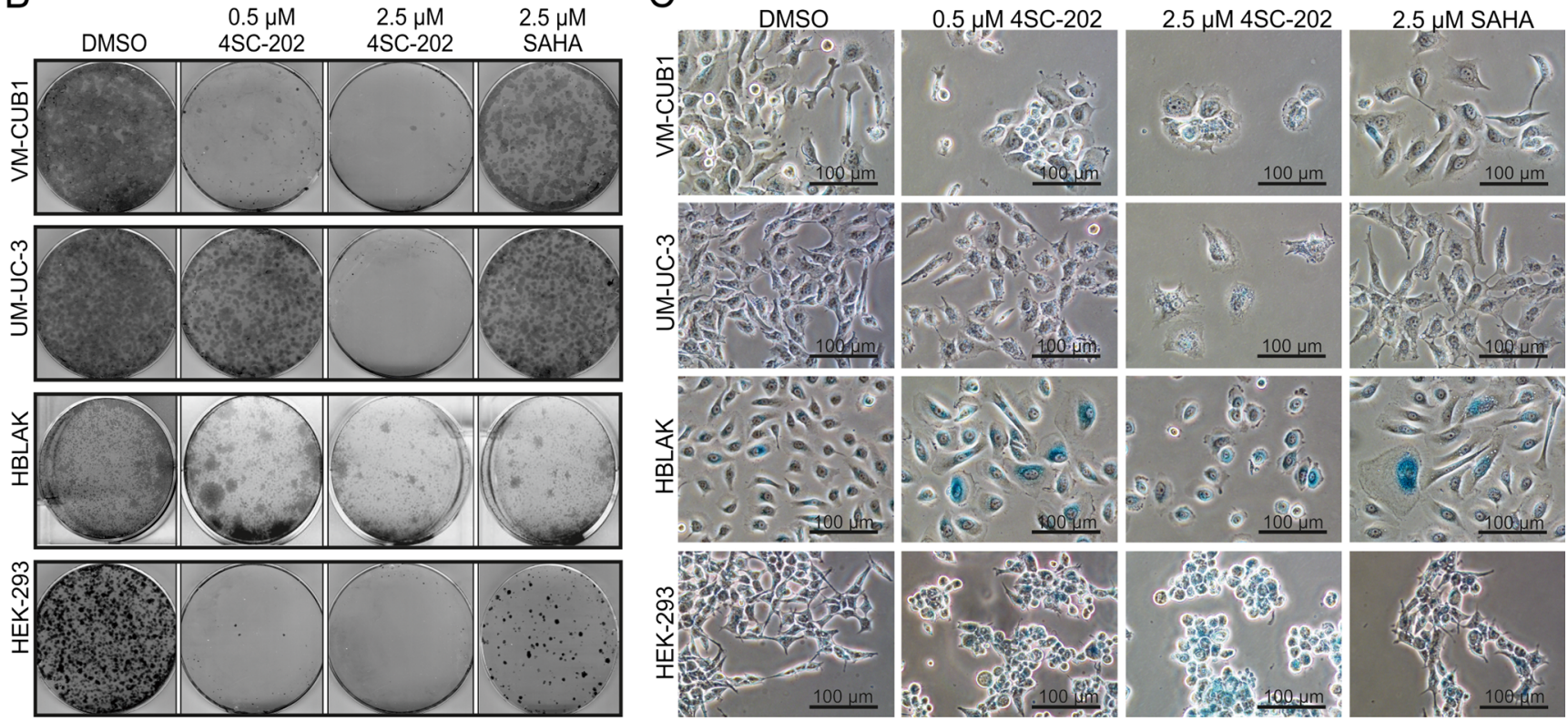

control cell line HBLAK and non-urothelial control HEK-293 cells. Cells

Fig. 2 Morphology, clonogenicity and senescence following 4SC-202 treatment in UCCs and control cells. a Morphology (additional comparison to romidepsin and givinostat treatment), b Giemsa-staining of grown colonies and $\mathbf{c}$ senescence associated $\beta$-Gal staining of inhibitor treated VM-CUB1 and UM-UC-3 cells in comparison to the urothelial were treated with DMSO, two different concentrations of 4SC-202 $(0.5$ and $2.5 \mu \mathrm{M}$ ), $3 \mathrm{nM}$ romidepsin, $0.5 \mu \mathrm{M}$ givinostat or $2.5 \mu \mathrm{M}$ SAHA $(48 \mathrm{~h})$. Phase-contrast images are shown at a $20 \times$ magnification

significant increase in caspase-3/7 activity after SAHA treatment was observed only in UM-UC-3 cells, while treatment with 4SC-202 markedly increased caspase-3/7 activity in all cell lines, especially at the higher concentration. Of note, after treatment with the lower concentration $(0.5 \mu \mathrm{M})$ of $4 \mathrm{SC}-202$, caspase-3/7 activity was only elevated after $48 \mathrm{~h}$. Notably, caspase-3/7 activity in HBLAK cells was only transiently increased after 24 h (Fig. 3a). More efficient induction of 
apoptosis by $4 \mathrm{SC}-202$ as compared to SAHA was also evidenced by enhanced cleaved PARP detected by western blotting (Fig. 3b) and in flow-cytometric quantification of apoptosis by Annexin V/PI staining (Fig. 3d, supplemental Fig. S2 in Online Resource 2). In addition to markers of apoptosis, significant release of LDH indicating necrotic cell death was detected in HDACi treated UM-UC-3 cells after $48 \mathrm{~h}$ incubation (Fig. 3c). Annexin V/PI staining suggested a mixture of apoptotic and necrotic cell death, with a strong increase in early apoptotic and late apoptotic/necrotic cells and a slight increase of necrotic cells especially after treatment with $2.5 \mu \mathrm{M} 4 \mathrm{SC}-202$ in both VM-CUB1 and UM-UC-3 cells (Fig. 3d, supplemental Fig. S2 in Online Resource 2). To confirm induction of apoptosis and necrosis, VM-CUB1 and UM-UC-3 UCCs were treated with $4 \mathrm{SC}-202$ for $48 \mathrm{~h}$ in the presence of Q-VD-OPh (pan-caspase inhibitor) or Necrox-2 (necrosis inhibitor) (Fig. 4). As positive controls, UCCs were treated with etoposide (apoptosis) and $\mathrm{H}_{2} \mathrm{O}_{2}$ (necrosis). In VM-CUB1 cells, Q-VD-OPh largely prevented cell death induced by $0.5 \mu \mathrm{M}$, but not by $2.5 \mu \mathrm{M} 4 \mathrm{SC}-202$. In contrast, in UM-UC-3 cells the necrosis inhibitor Necrox-2, but not QVD-OPh had a positive effect on viability during treatment with 0.5 or $2.5 \mu \mathrm{M} 4 \mathrm{SC}-202$, indicating rather a necrotic cell death mechanism (Fig. 4).

\subsection{SC-202 Induces Strong Mitotic Disturbances in UC Cells}

Cell cycle analysis by flow cytometry revealed profound disturbances of the cell cycle by 4SC-202 treatment in all investigated cell lines (Fig. 5a). In particular, in VM-CUB1, UM-UC3 and HEK-293 cells the G2/M fraction was strongly increased, especially after treatment with $2.5 \mu \mathrm{M} 4 \mathrm{SC}-202$. An increased G1 fraction was more apparent only in HBLAK cells. Notably, after $48 \mathrm{~h}$ treatment cell cycle profiles became highly irregular, especially with $2.5 \mu \mathrm{M} 4 \mathrm{SC}-202$, prohibiting proper quantification of the cell cycle distribution (Fig. 5a). However, the accumulation of cells in the G2/M fraction appeared to subside over time and cells with aberrant DNA content became evident. A straightforward explanation for these observations is a disturbed and protracted passage through mitosis with unequal distribution of the DNA to daughter cells. No similar effects were seen after SAHA treatment.

The changes in the cell cycle profiles elicited by 4 SC-202 were not reflected in according changes in the expression of cyclins in VM-CUB1 and UM-UC-3 cells (Fig. 5b). Notably, induction of $\mathrm{p} 21^{\mathrm{CIP} 1}$, a classical marker of cell cycle arrest induction by HDAC inhibitors, was less prominent with 4SC-202 compared to SAHA in VM-CUB1 and UM-UC-3 cells after $24 \mathrm{~h}$ treatment. Significant $\mathrm{p} 21^{\mathrm{CIP} 1}$ induction was only detected in both UCCs after $48 \mathrm{~h}$ of 4 SC-202 treatment (Fig. $5 b$ ).

To further delineate the cell cycle disturbances, we investigated the nuclear morphology of DAPI-stained VM-CUB1
Fig. 3 Mechanisms of cell death upon 4SC-202 treatment in UCCs and control cells. a Caspase 3/7 activity and b protein expression levels of cleaved caspase 3 and cleaved PARP were quantified after treatment with 4SC-202 or SAHA for 24 and $48 \mathrm{~h}$ in VM-CUB1, UM-UC-3, HBLAK and HEK-293 cells. $\mathbf{c}$ LDH assay indicating necrotic cell death measured after 4SC-202 treatment in VM-CUB1 and UM-UC-3 cells. The percentage of $\mathrm{LDH}$ release is normalized to the lysis control. Bortezomib and actinomycin D were used as additional controls. d Induction of necrosis and apoptosis was additionally analyzed by combined Annexin V- and PI-staining in the UCCs VM-CUB1 and UM-UC-3 after treatment with 4SC-202 or SAHA for 24 and $48 \mathrm{~h}$. The percentages in this figure refer to viable cells, necrotic cells, early apoptotic cells and late apoptotic/necrotic cells, respectively. The calculated significances refer to the DMSO solvent control. cl-cleaved

and UM-UC-3 cells following 4SC-202 treatment (Fig. 6). Strikingly, after $24 \mathrm{~h}$ of $4 \mathrm{SC}-202$ treatment, a large proportion of nuclei was involved in irregular mitoses (highly condensed structures in upper level) or presented as strongly fragmented nuclei with many micronuclei. Interphase nuclei with normal morphology were rather infrequent. After $48 \mathrm{~h}$ of treatment, the proportion of irregular mitoses was lower and a higher amount of strongly fragmented nuclei was apparent (Fig. 6).

Next, we analyzed exemplarily in VM-CUB1 cells whether 4SC-202 (24 h) induces $\gamma$ H2A.X (phosphorylated histone H2A.X on $\mathrm{Ser}^{139}$ ), to determine to which extent double-strand breaks (DSBs) contribute to the cell cycle disturbances [31, 32]. As $\gamma \mathrm{H} 2 \mathrm{~A}$.X can also be induced by other forms of DNA damage [31], we additionally performed double-staining for 53-BP1, which colocalizes with $\gamma \mathrm{H} 2 \mathrm{~A}$.X in DSB foci. The $\gamma \mathrm{H} 2 \mathrm{~A} . \mathrm{X}$ signal was strongly increased after $24 \mathrm{~h}$ treatment with $2.5 \mu \mathrm{M}$ 4SC-202, with most of the cells displaying strong pan-nuclear $\gamma$ H2A.X staining (Fig. 7a). In a subpopulation $\gamma$ H2A.X was focally induced, typical of cells with an activated DNA damage response [31]. In VM-CUB1 cells treated with $0.5 \mu \mathrm{M} 4 \mathrm{SC}-202$, the effect was similar, but less strong. 53-BP1 colocalized in some nuclei with $\gamma \mathrm{H} 2 \mathrm{~A}$.X foci (especially after treatment with $0.5 \mu \mathrm{M} 4 \mathrm{SC}-202$ ), but in most of the 4SC-202 treated cells, pannuclear $\gamma \mathrm{H} 2 \mathrm{~A}$.X staining without colocalization with 53-BP1 appeared dominant (Fig. 7b).

\subsection{Inhibition of LSD1 May Contribute to the Action of 4SC-202 on UC Cells}

To investigate to which extent LSD1 inhibition by 4SC-202 might contribute to its activity in UC cells, we compared its effects (at 0.5 and $2.5 \mu \mathrm{M}$, after 24 and $48 \mathrm{~h}$ treatment) on viability, clonogenicity, cell cycle distribution and morphology to that of romidepsin $(3 \mathrm{nM})$ in combination with the LSD1 inhibitor SP2509 (SP2509). Romidepsin and SP2509 each alone and SAHA were also investigated in parallel. The concentration of SP2509 was chosen at its approximate $\mathrm{IC}_{50}$ (Hoffmann et al., to be published elsewhere). The results for the cell line VM-CUB1 are illustrated in Fig. 8, and results for UM-UC-3 are shown in Fig. S4 in Online Resource 2. LSD1 

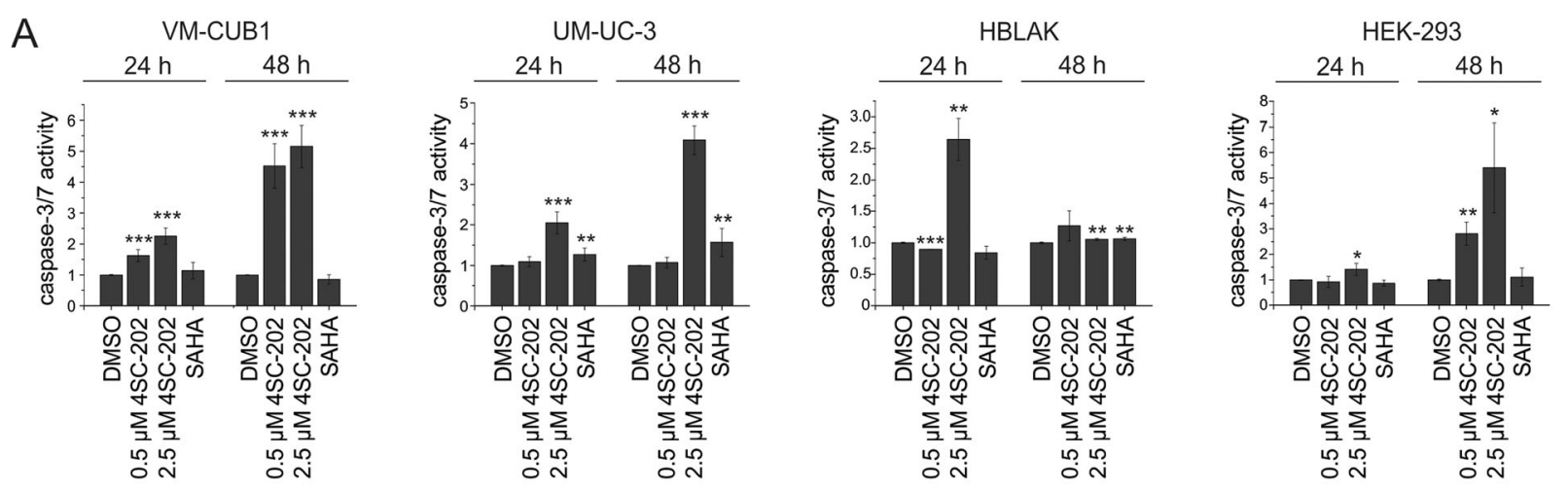

${ }^{*}=p<0.05 \quad{ }^{* *}=p<0.01^{* * *}=p<0.001$

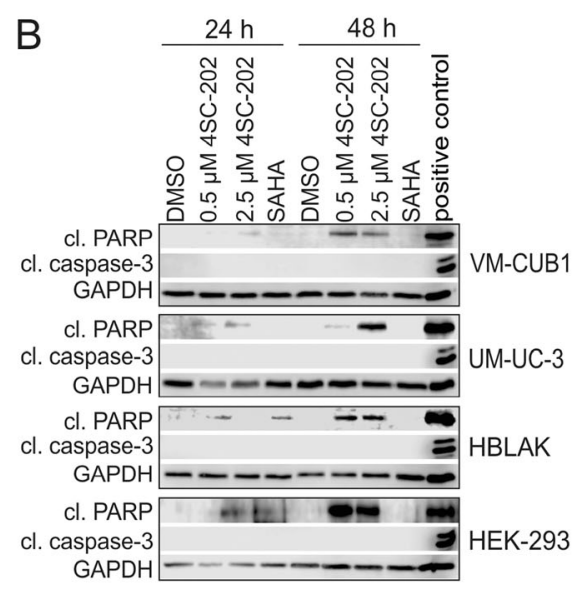

cl. PARP $89 \mathrm{kDa}$; cl. caspase $317 \mathrm{kDa}$; GAPDH 36 kDa
C

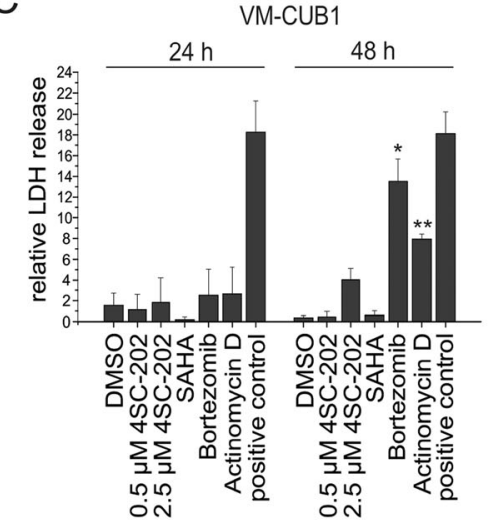

UM-UC-3

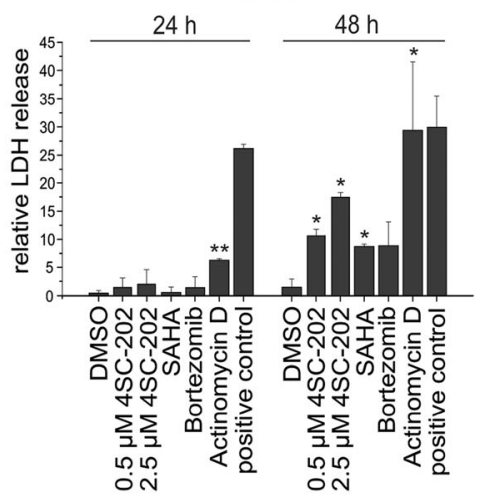

${ }^{*}=p<0.05^{* *}=p<0.01$

D

VM-CUB1 $24 \mathrm{~h}$

VM-CUB1 $48 \mathrm{~h}$
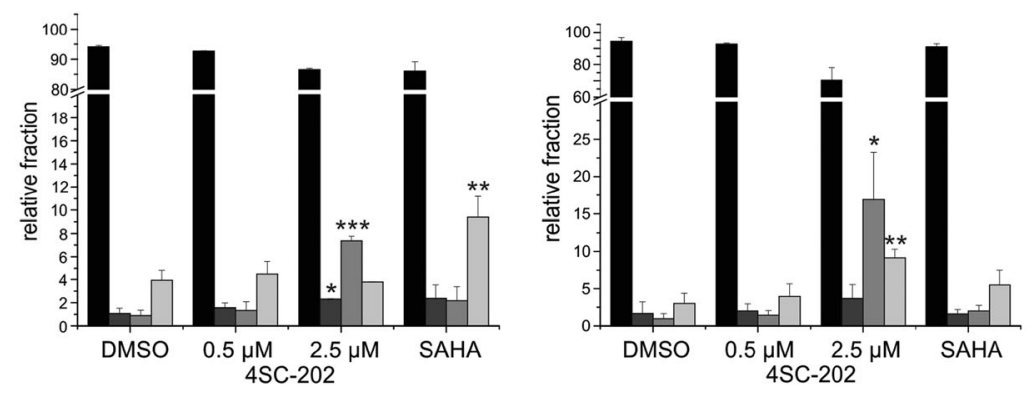

UM-UC-3 $24 \mathrm{~h}$

UM-UC-3 $48 \mathrm{~h}$
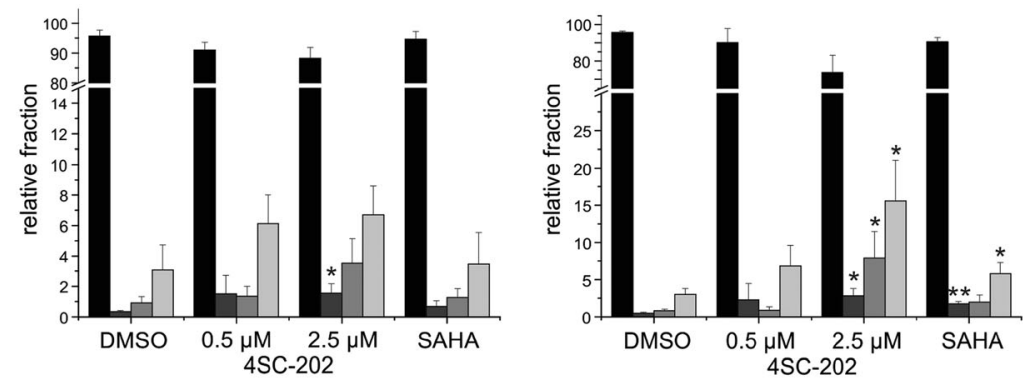

${ }^{*}=p<0.05 \quad{ }^{* *}=p<0.01^{* * *}=p<0.001$

- viable cells

$\square$ early apoptotic cells

necrotic cells

late apoptotic/necrotic cells 


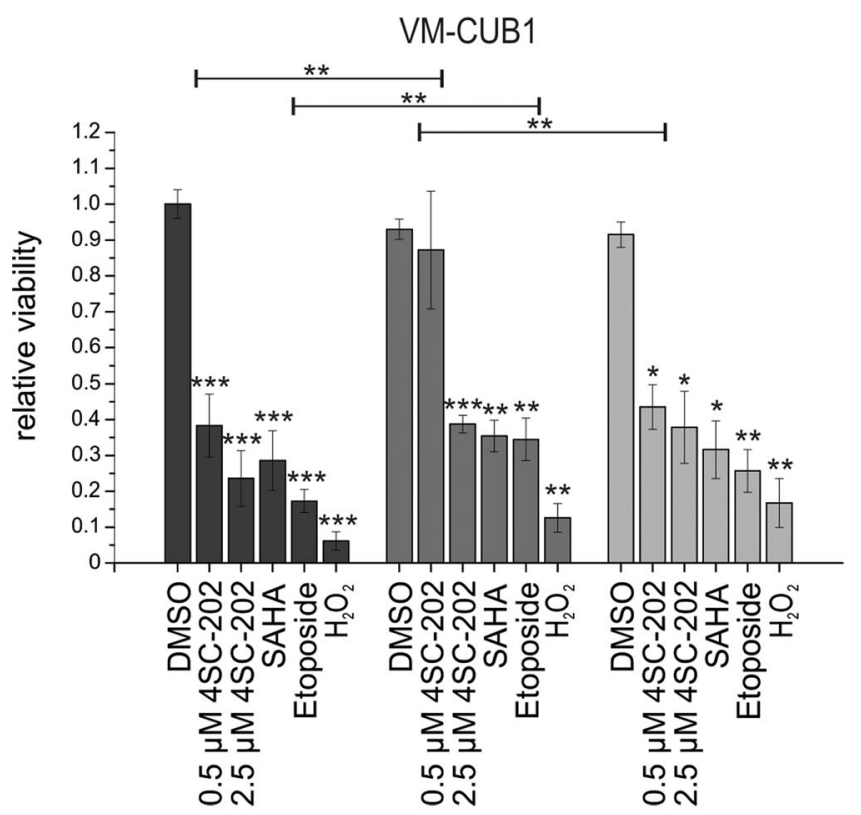

DMSO control

Q-VD-OPh

Necrox-2

Fig. 4 Investigation of apoptotic and necrotic cell death mechanisms in UCCs induced by class I HDAC inhibitor 4SC-202. Relative cell viability measured by MTT-assay in VM-CUB1 and UM-UC-3 cells following 4SC-202 treatment $(0.5 / 2.5 \mu \mathrm{M}, 48 \mathrm{~h})$ in combination with Q-VD-OPh (pan-caspase inhibitor) or Necrox-2 (necrosis inhibitor). Etoposide or

inhibition alone has rather weak effects on clonogenicity and cell cycle distribution at a concentration impairing viability comparable to treatment with romidepsin (Fig. 8b/c, Fig. S4B/C in Online Resource 2). However, its combination with romidepsin resulted in stronger effects on viability, clonogenicity and cell cycle disturbances (Fig. 8, Fig. S4 in Online Resource 2). For viability and clonogenicity, these effects were largely comparable with those of 4SC-202 at higher concentrations. Interestingly, however, clear differences between the two treatments were evident in the cell cycle profiles and morphological phenotypes of the treated cells (Fig. 8c/d, figure S4C/D in Online Resource 2). In general, concomitant SP2509 treatment appeared to accelerate the effects of romidepsin on cell viability, clonogenicity and alterations in cell cycle progression. In summary, although treatment with the combination of a class I-specific HDACi and an LSD1i elicited comparable effects to 4SC-202 on cell viability and clonogenicity, distinctive differences were observed in the cell cycle profiles and morphology (Fig. 8, Fig. S4 in Online Resource 2).

\section{Discussion}

In this preclinical study, we evaluated the suitability of the isotype-specific HDAC inhibitor 4SC-202 as a novel

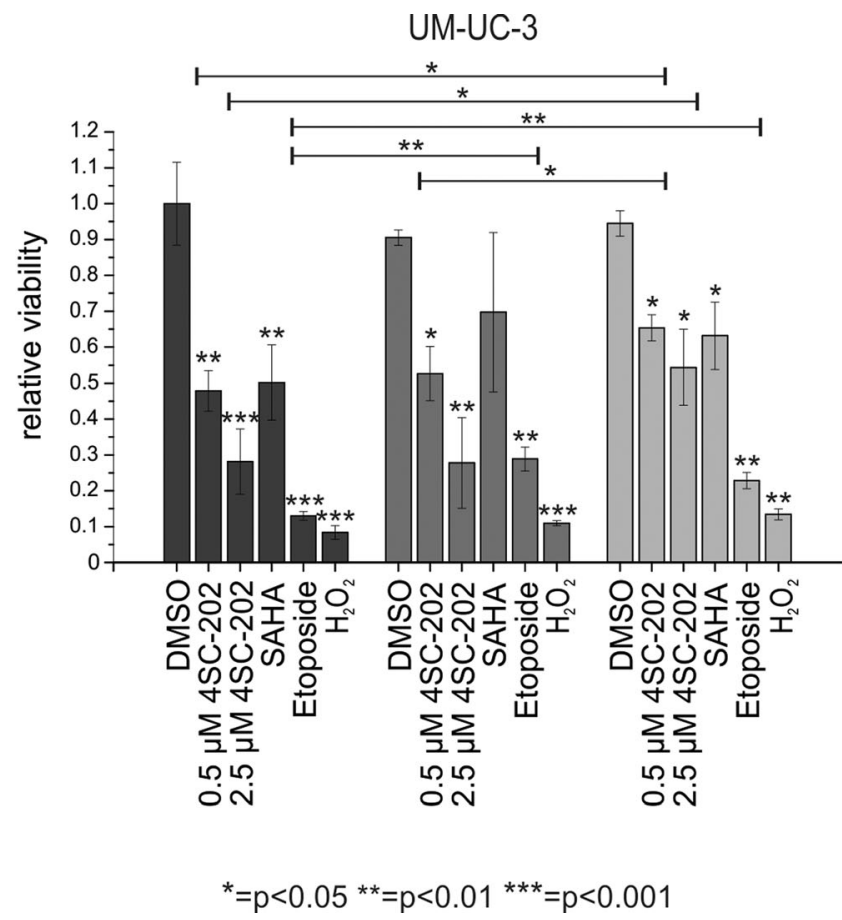

$\mathrm{H}_{2} \mathrm{O}_{2}$ treatments were used as positive controls. The determined significances of the treated cells relate to the DMSO solvent control. Additional significances between the different treatments are shown by brackets

treatment approach in UC. 4SC-202 significantly impaired proliferation of UCCs at submicromolar levels and was more efficacious in abrogating clonogenic growth than the panHDAC inhibitor SAHA. This is in line with our previous findings on the activity of two other isotype-specific HDAC inhibitors, romidepsin and givinostat, in UC [24]. Like 4SC202, these inhibitors also target rather specifically the class I HDACs 1 and 2, and treatment with either compound was more efficacious in inhibiting clonogenic growth as compared to SAHA. Taken together, these observations might mean that inhibition of additional HDACs beyond HDAC1-3 is counterproductive in the treatment of UCC. In support of this idea, we have previously reported that specific inhibition of HDAC6 or HDAC8 does not severely impede UCC proliferation or survival $[23,30]$.

Although 4SC-202 and romidepsin share the important HDACs 1 and 2 in their target profile, their effects on histone acetylation differ. This could have different reasons. First, 4SC-202 is a benzamide type HDACi exhibiting a slower on-kinetic as compared to the bicyclic peptide romidepsin. Second, the in vitro $\mathrm{IC}_{50}$ of romidepsin for HDAC1, HDAC2 and HDAC3 inhibition $\left(\mathrm{IC}_{50}: 0.10-0.38 \mathrm{nM}\right)$ [33] is significantly divergent from its $\mathrm{IC}_{50}$ in MTT assays for UC cells ( $\mathrm{IC}_{50} 72 \mathrm{~h}: 3.26-6.47 \mathrm{nM}$ ) [24]. Accordingly, for our experiments, we used romidepsin at a concentration close to its cellular $\mathrm{IC}_{50}$ values, which exceed the in vitro $\mathrm{IC}_{50}$ for 

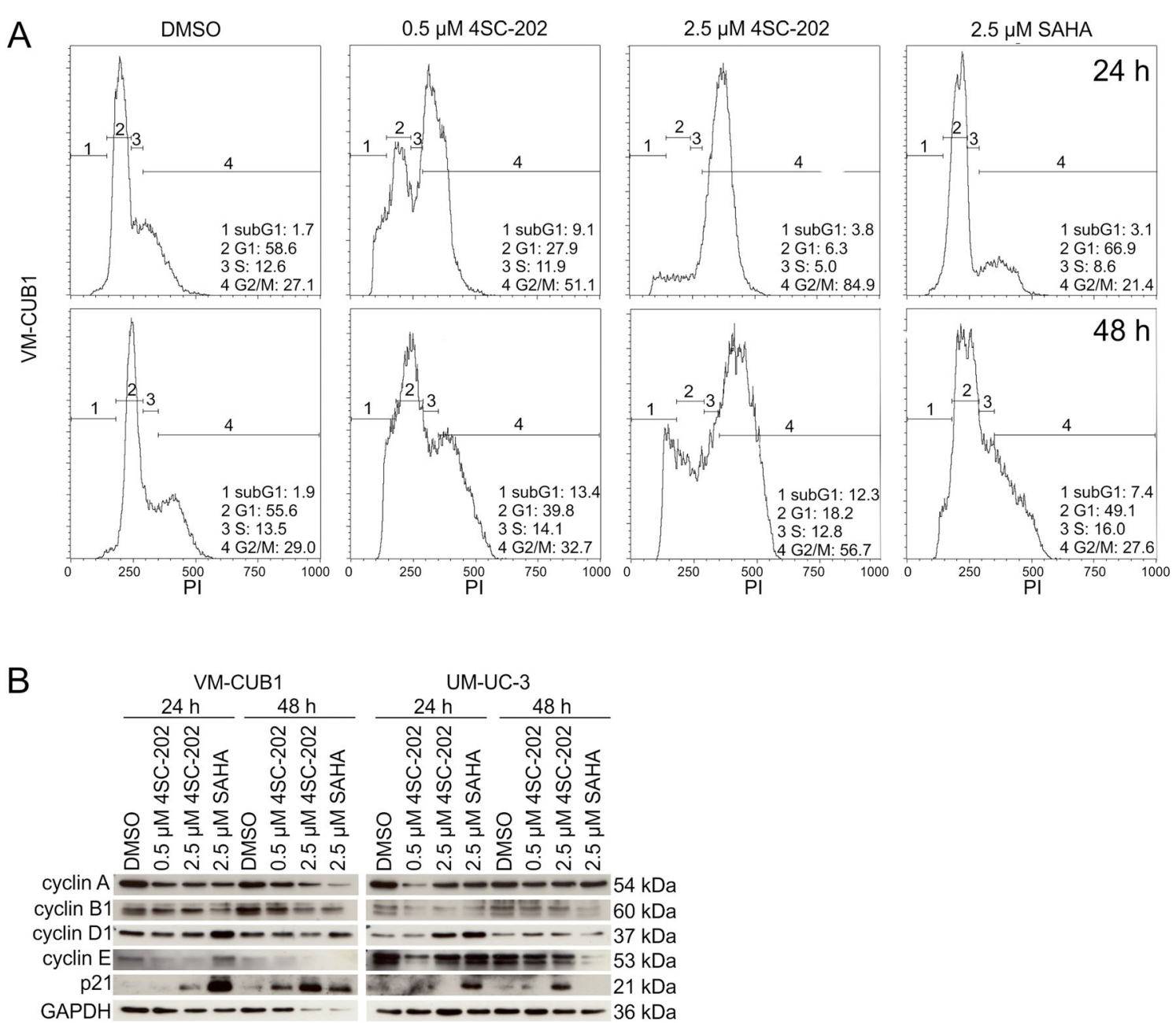

Fig. 5 Changes in cell cycle distribution and expression of cell cycle regulators after 4SC-202 treatment. a Cell cycle changes and amount of apoptotic cells (as sub G1 fraction) following 4SC-202 $(0.5 / 2.5 \mu \mathrm{M})$ or $2.5 \mu \mathrm{M}$ SAHA treatment $(24 / 48 \mathrm{~h})$ in VM-CUB1 cells were measured by cell cycle analysis using flow cytometry. DMSO is the solvent control.
Results for the cell lines UM-UC-3, HBLAK and HEK-293 are shown in supplemental Fig. S3 in Online Resource 2. b Cyclins (A, B1, D1, E) and p21 protein expression levels following 4 SC-202 $(0.5 / 2.5 \mu \mathrm{M})$ or $2.5 \mu \mathrm{M}$ SAHA treatment were quantified by western blot analysis in comparison to DMSO treatment in VM-CUB1 and UM-UC-3 cells (24/48 h)
HDAC1-3 activity by more than tenfold, resulting in broader hyperacetylation of histones. Third, treatment with 4SC-202 by inhibiting LSD1 may trigger methylation of lysine residues at some sites, which might interfere with acetylation. Fourth, apart from histone proteins, both compounds may substantially differ in their ability to promote hyperacetylation of nonhistone proteins, which may further impact the pattern of histone acetylation [34]. Finally, the action of individual HDACi depends on their ability to not only target specific HDACs, but also to inhibit cellular repressor complexes containing HDAC proteins [35]. Thereby, even HDACi with highly similar profiles in vitro could elicit different acetylation profiles in vivo.

Importantly, inhibition of proliferation and clonogenic growth upon treatment with 4SC-202 was likewise observed in non-cancerous cell lines at comparable concentrations. In comparison to romidepsin and givinostat, 4SC-202 had stronger effects especially on HEK-293 cells, whereas the immortalized urothelial HBLAK cells were less affected and inhibition of growth was rather due to senescence than cell death. Induction of senescence in non-cancerous cells by HDACi has been reported in several other instances. Therefore, the preferential activity of HDACi against tumor cells may rather result from the type of reaction elicited by the drugs [36] than the type of damage caused, as proposed by others [37]. 4SC-202 generally affects proliferating cells more strongly [38]. Accordingly, HBLAK cells that were growth arrested at confluence were much less sensitive than while proliferating. Induction of differentiation did not further diminish their sensitivity. Likewise, the activity of 4SC-202 was significantly higher towards proliferating as compared to arrested $\left(\mathrm{IC}_{50} 0.2 \mu \mathrm{M}\right.$ and $>10 \mu \mathrm{M}$, respectively) $\mathrm{RKO}$ colon carcinoma cells. Induction of apoptosis was also much stronger in proliferating than in arrested cell lines (detailed report provided upon request by H.K.). In contrast, HEK- 
Fig. 6 Aberrant nuclear morphology in 4SC-202 treated VM-CUB1 and UM-UC-3 cells. Nuclear staining with 4 ',6Diamidin-2-phenylindol (DAPI, blue) was performed to distinguish nuclear morphologies (interphase nuclei, mitosis, proapoptotic nuclei, micronuclei, irregular nuclei). Representative nuclear stainings are shown for the UCCs VM-CUB1 and UMUC-3. Cells were counterstained with rhodamine phalloidin. For each cell line, the upper panels show DMSO treated and the lower panels 4SC-202 (0.5/ $2.5 \mu \mathrm{M})$ and $2.5 \mu \mathrm{M}$ SAHA treated cells $(24 / 48 \mathrm{~h})$

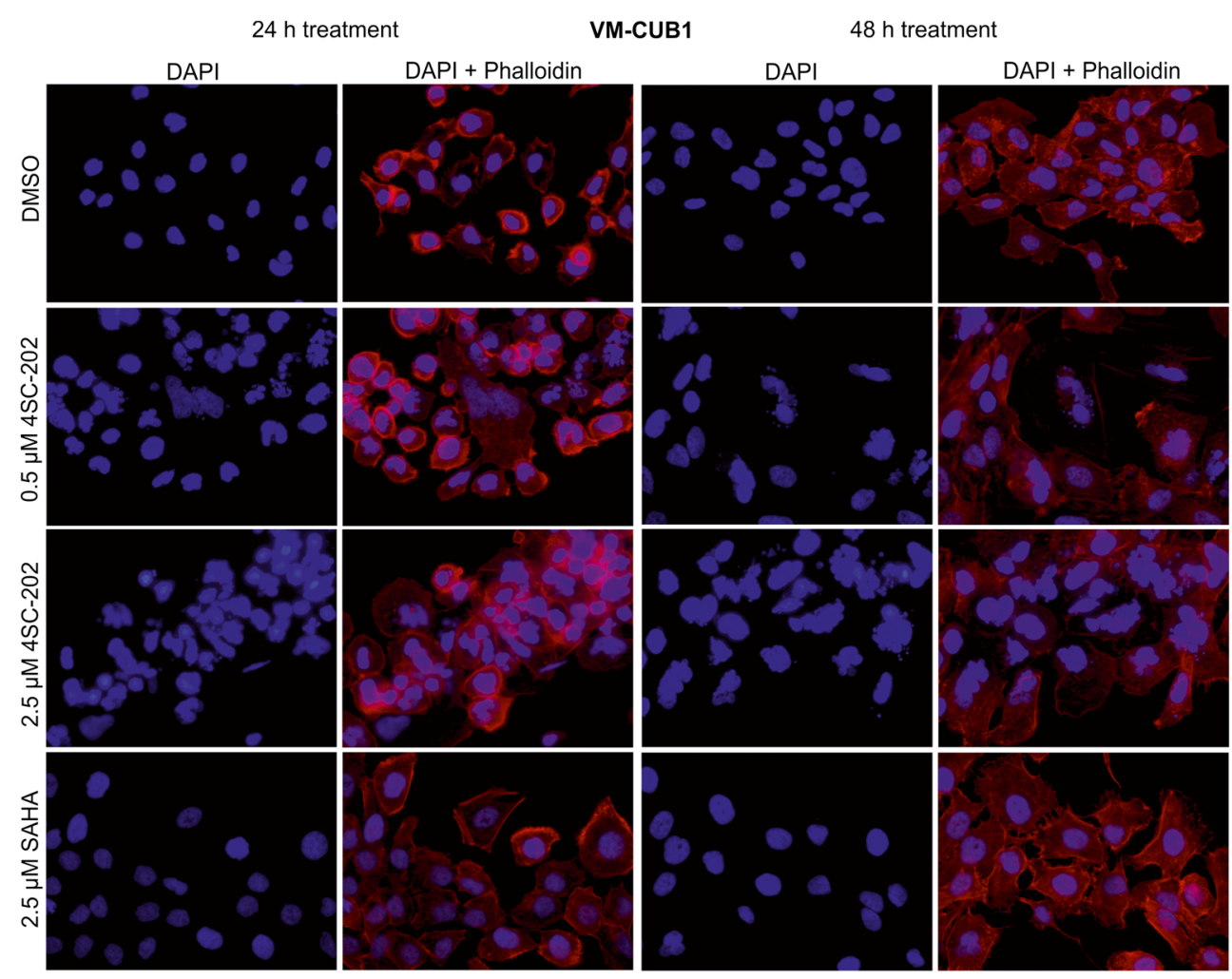

$24 \mathrm{~h}$ treatment

UM-UC-3

$48 \mathrm{~h}$ treatment

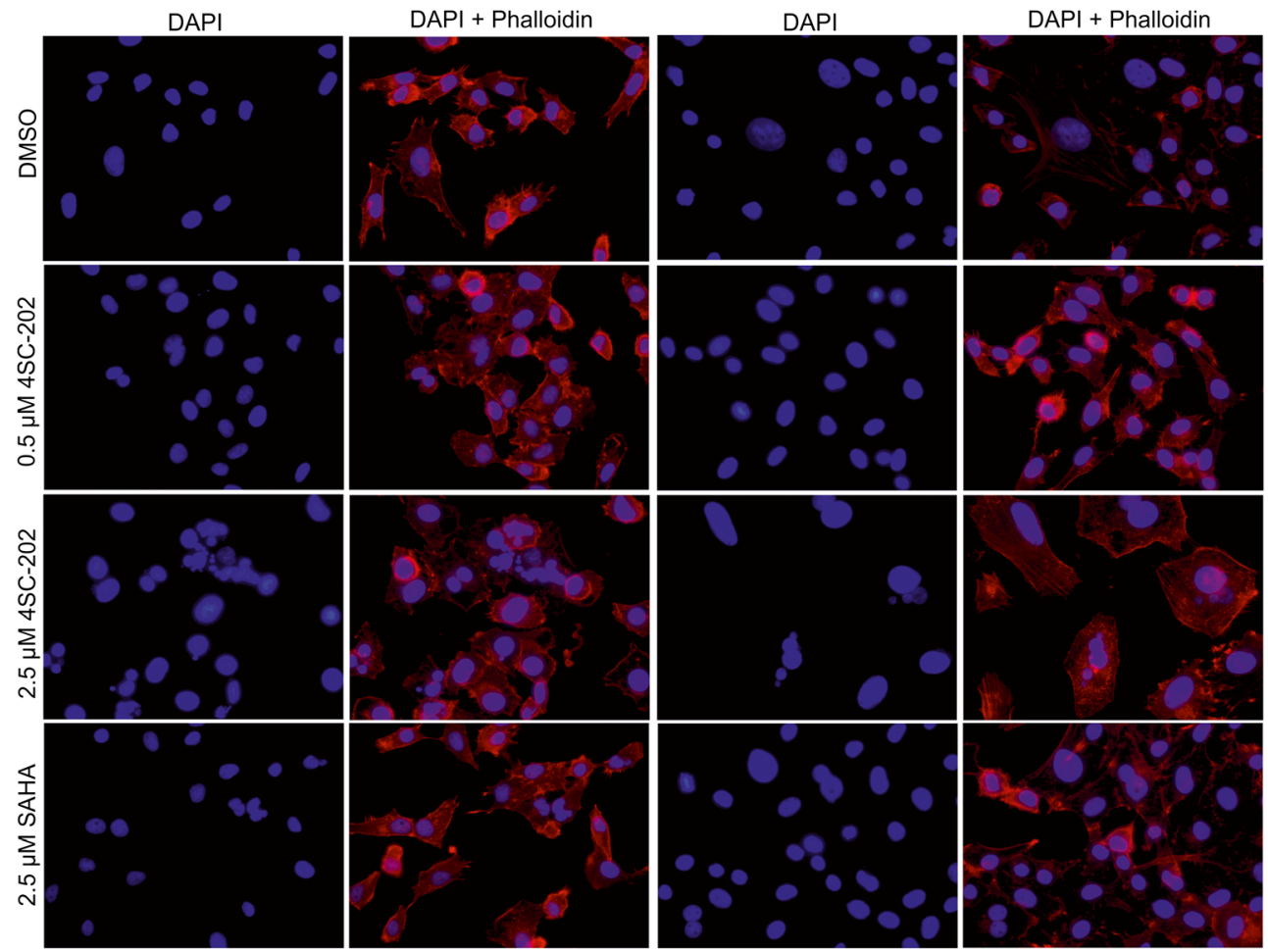

293 cells were notably more sensitive to 4 SC-202 than to romidepsin and givinostat. This difference could therefore be due to targets of 4SC-202 apart from HDACs. In particular,
4SC-202 may unfold its antineoplastic activity in UC by impacting on LSD1 and Wnt and Hedgehog signaling (data presented at MMC Cancer Stem Cell Symposium 2014 \& 


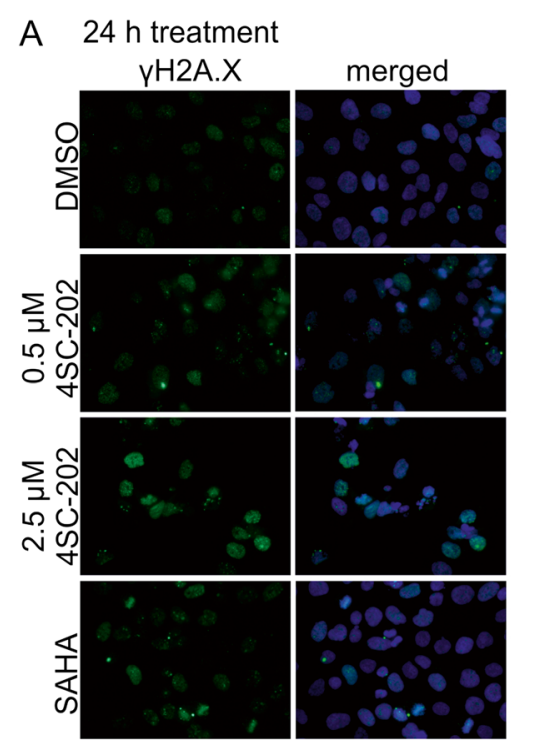

Fig. 7 DNA damage-associated foci in VM-CUB1 cells following 4SC202 treatment. a Immunofluorescence staining of $\gamma \mathrm{H} 2 \mathrm{~A} . \mathrm{X}$ (green) and nuclei staining with 4',6-Diamidin-2-phenylindol (DAPI, blue) in VMCUB1 cells after $24 \mathrm{~h}$ treatment $(40 \times$ magnification). b Representative
B $24 \mathrm{~h}$ treatment

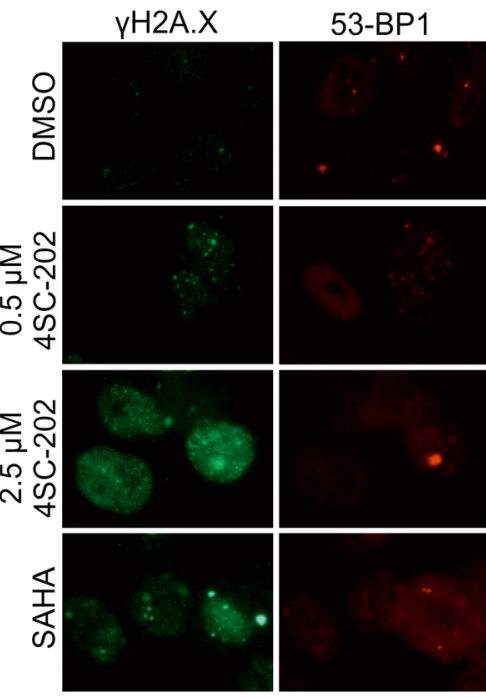

$\mathrm{YH} 2 \mathrm{~A} \mathrm{X}$
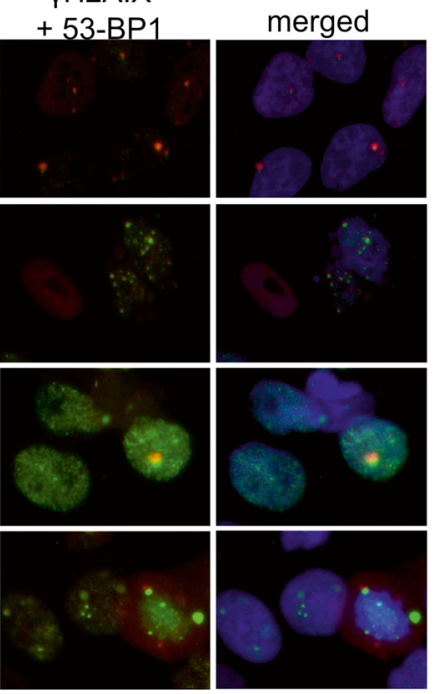

immunofluorescence double staining of $\gamma \mathrm{H} 2 \mathrm{~A} . \mathrm{X}$ (green) and 53-BP1 (red) in VM-CUB1 treated cells. The upper panels show DMSO treated and the lower panels shows 4SC-202 $(0.5 / 2.5 \mu \mathrm{M})$ and SAHA treated cells $(24 \mathrm{~h})$ as indicated

Keystone Symposium "Stem Cells and Cancer" 2014, data available online at https://4SC.de). Albeit not caused by canonical mechanisms, dysregulation of WNT and Hedgehog signaling has also been observed in bladder cancer $[39,40]$. In our experiments, no effect on WNT or Hedgehog signaling by 4 SC-202 could be demonstrated in $\mathrm{UC}$ cell lines (data not shown).

Inhibition of LSD1 alone also has limited effects on UC cell lines (Hoffmann et al., to be published elsewhere). However, LSD1 inhibition appeared to enhance and especially to accelerate the action of the HDAC $1 / 2$ inhibitor romidepsin. The combined action of the two compounds, however, remained different from that of 4SC-202, especially with respect to the cell cycle and morphology. The details of this interaction require further study. Interestingly, a synergism between LSD1 and HDAC inhibition has been demonstrated for glioblastoma, where combined inhibition of LSD1 and HDACs synergistically induce apoptotic cell death in glioblastoma cells, but not in benign control cells [41].

In general, HDAC inhibitors are thought to exert their antineoplastic efficacy on cancer cells mainly by inducing apoptosis $[42,43]$ and cell cycle arrest, preferably at the G1/S checkpoint [44]. In contrast, necrosis induced by treatment with HDAC inhibitors has been reported only occasionally. For example, necrosis was observed in melanoma cells with mutant B-RAF upon co-treatment with a B-RAF-inhibitor and either panobinostat or SAHA [45]. In UC cells treated with 4SC-202, we observed a mixture of apoptotic and necrotic cell death. Moreover, G1 arrest was clearly not induced. Rather, especially after $24 \mathrm{~h}$ and with higher concentrations of 4SC202, the UCCs accumulated in the G2/M phase. We have observed this response already in previous studies especially with class I HDAC-specific inhibitors [20, 23, 24, 30], but it was even more pronounced upon treatment with 4SC-202. The lack of a G1 arrest in UCCs may be explained by the severe defects in the G1/S checkpoint characteristic for that tumor type [46]. It is nevertheless possible that 4SC-202 acts primarily at the $\mathrm{G} 2 / \mathrm{M}$ phase. This contention is supported by the early and strong accumulation of cells in the G2/M phase, but even more so by the morphological observations of disturbed mitoses and pan-nuclear DNA damage. In fact, the various cellular phenotypes observed after 4SC-202 treatment fit those described for cells undergoing mitotic catastrophe. Preclinical investigations in other cancers have likewise provided evidence that $4 \mathrm{SC}-202$ interferes with the normal formation of the mitotic spindle leading to a collapsed spindle apparatus and multiple nucleation centers [38]. In keeping with our observations, very recently, 4SC-202 was reported to induce $\mathrm{G} 2 / \mathrm{M}$ arrest and apoptosis in colorectal cancer cells [47]. Another very recent study detected apoptosis induction in hepatocellular carcinoma cells, but did not investigate effects on the cell cycle [48]. Indeed, acetylation/deacetylation cycles of various mitotic proteins and histones $[49,50]$ are important for mitosis and abnormal mitosis triggers p53dependent cell cycle arrest or cell death [51]. Therefore, our findings are best rationalized by the following hypothesis. Treatment with 4SC-202 disturbs mitosis in the first cell cycle leading to accumulation of cells in the $\mathrm{G} 2 / \mathrm{M}$ phase, followed by irregular cell division, resulting in cells with apparent subG1 and S-phase content that undergo secondary necrosis or apoptosis. Notably, p53 is defective in almost all invasive UC tissues and cell lines [52, 53], which may impede their 

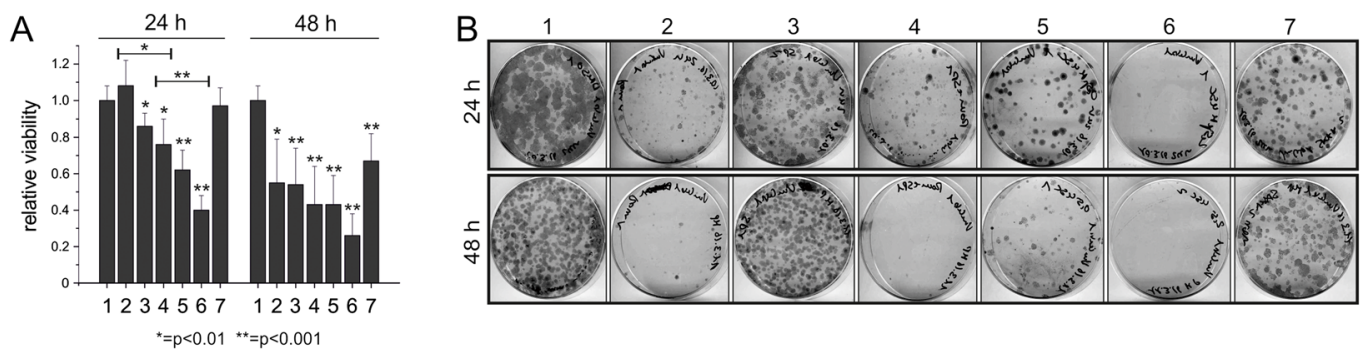

1: DMSO

2: $3 \mathrm{nM}$ Romidepsin

4: $3 \mathrm{nM}$ Romidepsin + $0.75 \mu \mathrm{M}$ SP2509

5: $0.5 \mu \mathrm{M} 4 \mathrm{SC}-202$

6: $2.5 \mu \mathrm{M} 4 \mathrm{SC}-202$

${ }^{*}=p<0.01{ }^{* *}=p<0.001$
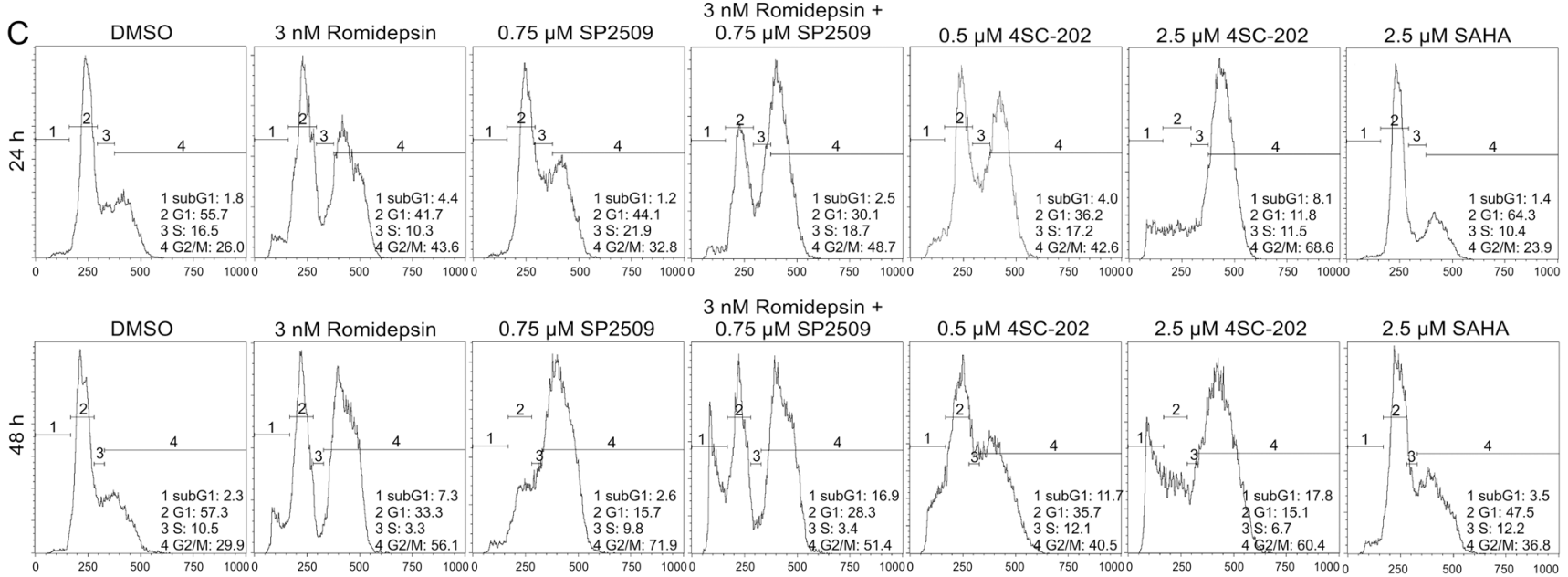

D
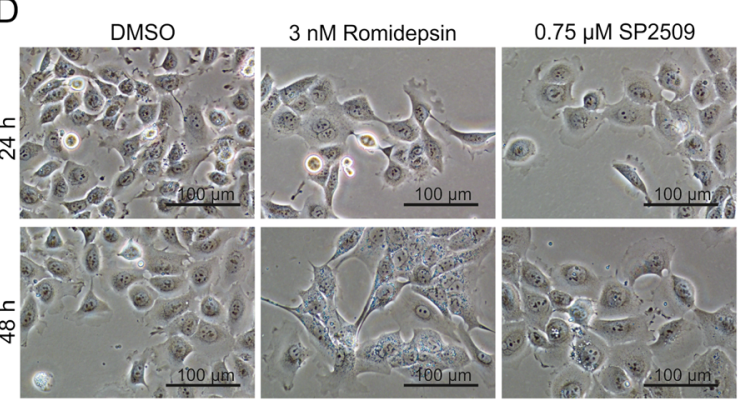

$3 \mathrm{nM}$ Romidepsin +
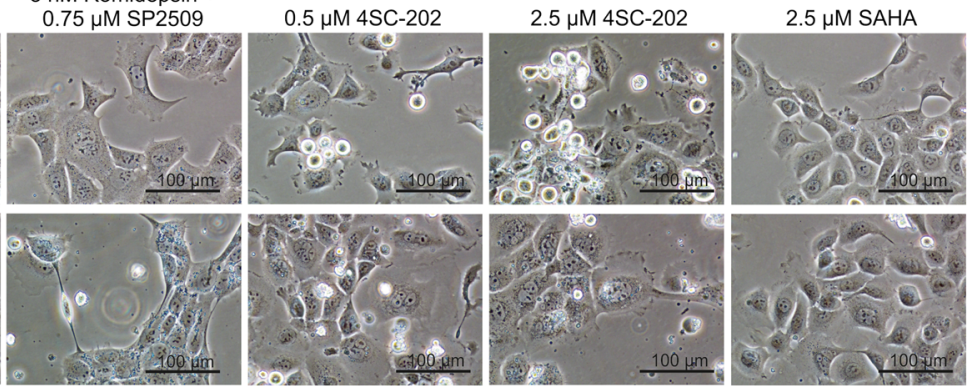

Fig. 8 Comparison of LSD1 plus HDAC1/2 inhibitor combination vs. 4SC-202 treatment in VM-CUB1 cells. Changes in viability (CellTiterGlo®, a), clonogenicity (Giemsa-staining of grown colonies, b), cell cycle distribution and amount of apoptotic cells (as sub-G1 fraction; cell cycle analysis using flow cytometry, c) and morphology (d) of

VM-CUB1 cells after treatment with $3 \mathrm{nM}$ romidepsin, $0.75 \mu \mathrm{M}$ SP2509 or both $(24 \mathrm{~h}$ or $48 \mathrm{~h})$ in comparison to two different concentrations of 4SC-202 (0.5 and $2.5 \mu \mathrm{M} ; 24 / 48 \mathrm{~h})$. Phase-contrast images are shown at a $20 \times$ magnification. Corresponding data for UMUC-3 cells are shown in Fig. S4 in Online Resource 2

ability to induce apoptosis after a mitotic catastrophe and contribute to the unusual mode of cell death observed here.

\section{Conclusion}

4SC-202 exerts a significant antineoplastic effect on UC cells in our preclinical evaluation. The efficacy of the drug was higher as compared to the pan-HDAC inhibitor SAHA. The antineoplastic effect was characterized by combined induction of apoptotic and necrotic cell death. Cell death is likely to be a consequence of cell cycle disruption characterized especially by mitotic disturbances. In summary, use of $4 \mathrm{SC}-202$ is a promising approach for the treatment of urothelial cancer that deserves further investigation.

\section{Compliance with Ethical Standards}

Authors' Contributions GN, WAS, MJH, HK and MP conceived and designed the study. HK provided 4SC-202 inhibitor from 4SC AG. MP performed most experiments, MJH carried out additional experiments. MP, WAS and GN carried out data analysis. MP and GN prepared the initial manuscript. WAS, MJH and HK contributed to the manuscript. GN supervised the project with the support of WAS. All authors read and approved the final manuscript.

Funding The work was supported by a grant from the Deutsche Forschungsgemeinschaft (DFG) to GN (Grant-No.: NI 1398/1-1). 
Conflicts of Interest WAS has received a grant for preclinical investigation of 4SC-201 from 4SC AG in the past. 4SC-202 was provided by 4SC AG to GN. 4SC AG paid fees for open access publication; further funding was not granted for this study. $\mathrm{HK}$ is an employee of 4SC AG. $\mathrm{MP}$ and MJH declare no further conflicts of interest.

Open Access This article is distributed under the terms of the Creative Commons Attribution-NonCommercial 4.0 International License (http:// creativecommons.org/licenses/by-nc/4.0/), which permits any noncommercial use, distribution, and reproduction in any medium, provided you give appropriate credit to the original author(s) and the source, provide a link to the Creative Commons license, and indicate if changes were made.

\section{References}

1. De Santis M, Bellmunt J, Mead G, Kerst JM, Leahy M, Maroto P, et al. Randomized phase II/III trial assessing gemcitabine/ carboplatin and methotrexate/carboplatin/vinblastine in patients with advanced urothelial cancer who are unfit for cisplatin-based chemotherapy: EORTC study 30986. J Clin Oncol. 2012;30(2): 191-9.

2. Sternberg CN, de Mulder PH, Schornagel JH, Theodore C, Fossa $\mathrm{SD}$, van Oosterom AT, et al. Randomized phase III trial of highdose-intensity methotrexate, vinblastine, doxorubicin, and cisplatin (MVAC) chemotherapy and recombinant human granulocyte colony-stimulating factor versus classic MVAC in advanced urothelial tract tumors: European Organization for Research and Treatment of Cancer Protocol no. 30924. J Clin Oncol. 2001;19(10):2638-46.

3. von der Maase H, Sengelov L, Roberts JT, Ricci S, Dogliotti L, Oliver T, et al. Long-term survival results of a randomized trial comparing gemcitabine plus cisplatin, with methotrexate, vinblastine, doxorubicin, plus cisplatin in patients with bladder cancer. $\mathrm{J}$ Clin Oncol. 2005;23(21):4602-8.

4. Reddy K. Phase III, study of sunitinib malate (SU11248) versus interferon-alpha as first-line treatment in patients with metastatic renal cell carcinoma. Clin Genitourin Cancer. 2006;5(1):23-5.

5. Escudier B, Eisen T, Stadler WM, Szczylik C, Oudard S, Staehler $\mathrm{M}$, et al. Sorafenib for treatment of renal cell carcinoma: final efficacy and safety results of the phase III treatment approaches in renal cancer global evaluation trial. J Clin Oncol: Off J Am Soc Clin Oncol. 2009;27(20):3312-8. doi:10.1200/JCO.2008.19.5511.

6. Motzer RJ, Escudier B, Oudard S, Hutson TE, Porta C, Bracarda S, et al. Efficacy of everolimus in advanced renal cell carcinoma: a double-blind, randomised, placebo-controlled phase III trial. Lancet. 2008;372(9637):449-56. doi:10.1016/S0140-6736(08) 61039-9.

7. Ghosh M, Brancato SJ, Agarwal PK, Apolo AB. Targeted therapies in urothelial carcinoma. Curr Opin Oncol. 2014;26(3):305-20. doi: 10.1097/CCO.0000000000000064.

8. Niegisch G, Lorch A, Albers P. Chemotherapy for urothelial cancer of the bladder - update 2012. Aktuelle Urol. 2012;43(6):412-9. doi:10.1055/s-0032-1327699.

9. Knievel J, Schulz WA, Greife A, Hader C, Lubke T, Schmitz I, et al. Multiple mechanisms mediate resistance to sorafenib in urothelial cancer. Int J Mol Sci. 2014;15(11):20500-17.

10. de Ruijter AJ, van Gennip AH, Caron HN, Kemp S, van Kuilenburg AB. Histone deacetylases (HDACs): characterization of the classical HDAC family. Biochem J. 2003;370(Pt 3):737-49. doi:10.1042/BJ20021321
11. Gregoretti IV, Lee YM, Goodson HV. Molecular evolution of the histone deacetylase family: functional implications of phylogenetic analysis. J Mol Biol. 2004;338(1):17-31. doi:10.1016/j.jmb.2004. 02.006.

12. Witt O, Deubzer HE, Milde T, Oehme I. HDAC family: what are the cancer relevant targets? Cancer Lett. 2009;277(1):8-21. doi:10. 1016/j.canlet.2008.08.016.

13. Weichert W, Roske A, Gekeler V, Beckers T, Ebert MP, Pross M, et al. Association of patterns of class I histone deacetylase expression with patient prognosis in gastric cancer: a retrospective analysis. Lancet Oncol. 2008;9(2):139-48. doi:10.1016/S1470-2045(08) 70004-4.

14. Weichert W, Roske A, Gekeler V, Beckers T, Stephan C, Jung K, et al. Histone deacetylases 1,2 and 3 are highly expressed in prostate cancer and HDAC2 expression is associated with shorter PSA relapse time after radical prostatectomy. Br J Cancer. 2008;98(3): 604-10. doi:10.1038/sj.bjc.6604199.

15. Weichert W, Denkert C, Noske A, Darb-Esfahani S, Dietel M, Kalloger SE, et al. Expression of class I histone deacetylases indicates poor prognosis in endometrioid subtypes of ovarian and endometrial carcinomas. Neoplasia. 2008;10(9):1021-7.

16. Yang XJ, Seto E. The Rpd3/Hda1 family of lysine deacetylases: from bacteria and yeast to mice and men. Nat Rev Mol Cell Biol. 2008;9(3):206-18. doi:10.1038/nrm2346.

17. Grunstein M. Histone acetylation in chromatin structure and transcription. Nature. 1997;389(6649):349-52. doi:10.1038/38664.

18. Valente S, Mai A. Small-molecule inhibitors of histone deacetylase for the treatment of cancer and non-cancer diseases: a patent review (2011-2013). Expert Opin Ther Pat. 2014. doi:10.1517/13543776. 2014.877446.

19. Ververis K, Hiong A, Karagiannis TC, Licciardi PV. Histone deacetylase inhibitors (HDACIs): multitargeted anticancer agents. Biol: Targets Ther. 2013;7:47-60. doi:10.2147/BTT.S29965.

20. Niegisch G, Knievel J, Koch A, Hader C, Fischer U, Albers P, et al. Changes in histone deacetylase (HDAC) expression patterns and activity of HDAC inhibitors in urothelial cancers. Urol Oncol. 2013;31(8):1770-9. doi:10.1016/j.urolonc.2012. 06.015 .

21. Vallo S, Xi W, Hudak L, Juengel E, Tsaur I, Wiesner C, et al. HDAC inhibition delays cell cycle progression of human bladder cancer cells in vitro. Anti-Cancer Drugs. 2011;22(10):1002-9. doi: 10.1097/CAD.0b013e32834a2c70.

22. Oehme I, Deubzer HE, Wegener D, Pickert D, Linke JP, Hero B, et al. Histone deacetylase 8 in neuroblastoma tumorigenesis. Clin Cancer Res. 2009;15(1):91-9. doi:10.1158/1078-0432.CCR-080684.

23. Lehmann M, Hoffmann MJ, Koch A, Ulrich SM, Schulz WA, Niegisch G. Histone deacetylase 8 is deregulated in urothelial cancer but not a target for efficient treatment. J Exp Clin Cancer Res: CR. 2014:33:59. doi:10.1186/s13046-014-0059-8.

24. Pinkerneil M, Hoffmann MJ, Deenen R, Köhrer K, Arent T, Schulz WA, et al. Inhibition of class I histone deacetylases 1 and 2 promotes urothelial carcinoma cell death by various mechanisms. Mol Cancer Ther. 2016;15(2):299-312. doi:10.1158/1535-7163.MCT15-0618.

25. Tresckow B, Gundermann S, Eichenauer DA, Aulitzky WE, Göbeler M, Sayehli C et al. First-in-human study of 4SC-202, a novel oral HDAC inhibitor in advanced hematologic malignancies (TOPAS study). Journal of Clinical Oncology. 2014;32(supplement 5):abstr. 8559

26. Swiatkowski S, Seifert HH, Steinhoff C, Prior A, Thievessen I, Schliess F, et al. Activities of MAP-kinase pathways in normal uroepithelial cells and urothelial carcinoma cell lines. Exp Cell Res. 2003;282(1):48-57.

27. Cross WR, Eardley I, Leese HJ, Southgate J. A biomimetic tissue from cultured normal human urothelial cells: analysis of 
physiological function. Am J Physiol Renal Physiol. 2005;289(2): F459-68. doi:10.1152/ajprenal.00040.2005.

28. Nicoletti I, Migliorati G, Pagliacci MC, Grignani F, Riccardi C. A rapid and simple method for measuring thymocyte apoptosis by propidium iodide staining and flow cytometry. J Immunol Methods. 1991;139(2):271-9.

29. Shechter D, Dormann HL, Allis CD, Hake SB. Extraction, purification and analysis of histones. Nat Protoc. 2007;2(6):1445-57. doi:10.1038/nprot.2007.202.

30. Rosik L, Niegisch G, Fischer U, Jung M, Schulz WA, Hoffmann MJ. Limited efficacy of specific HDAC6 inhibition in urothelial cancer cells. Cancer Biol Ther. 2014;15(6):742-57.

31. Bonner WM, Redon CE, Dickey JS, Nakamura AJ, Sedelnikova OA, Solier S, et al. GammaH2AX and cancer. Nat Rev Cancer. 2008;8(12):957-67. doi:10.1038/nrc2523.

32. Rogakou EP, Pilch DR, Orr AH, Ivanova VS, Bonner WM. DNA double-stranded breaks induce histone H2AX phosphorylation on serine 139. J Biol Chem. 1998;273(10):5858-68.

33. Wei DG, Chiang V, Fyne E, Balakrishnan M, Barnes T, Graupe M, et al. Histone deacetylase inhibitor romidepsin induces HIV expression in CD4 T cells from patients on suppressive antiretroviral therapy at concentrations achieved by clinical dosing. PLoS Pathog. 2014;10(4), e1004071. doi:10.1371/journal.ppat.1004071.

34. Scholz C, Weinert BT, Wagner SA, Beli P, Miyake Y, Qi J, et al. Acetylation site specificities of lysine deacetylase inhibitors in human cells. Nat Biotechnol. 2015;33(4):415-23. doi:10.1038/nbt.3130.

35. Bantscheff M, Hopf C, Savitski MM, Dittmann A, Grandi P, Michon AM, et al. Chemoproteomics profiling of HDAC inhibitors reveals selective targeting of HDAC complexes. Nat Biotechnol. 2011;29(3):255-65. doi:10.1038/nbt.1759.

36. Halsall JA, Turan N, Wiersma M, Turner BM. Cells adapt to the epigenomic disruption caused by histone deacetylase inhibitors through a coordinated, chromatin-mediated transcriptional response. Epigenetics Chromatin. 2015;8:29. doi:10.1186/s13072015-0021-9.

37. Lee JH, Choy ML, Ngo L, Foster SS, Marks PA. Histone deacetylase inhibitor induces DNA damage, which normal but not transformed cells can repair. Proc Natl Acad Sci U S A. 2010;107(33):14639-44. doi:10.1073/pnas.1008522107.

38. Henning SW, Doblhofer R, Kohlhof H, Jankowsky R, Maier T, Beckers T, et al. Preclinical characterization of 4SC-202, a novel isotype specific HDAC inhibitor. Eur J Cancer Suppl. 2010;8(7):61 (abstr. 178).

39. Fei DL, Sanchez-Mejias A, Wang Z, Flaveny C, Long J, Singh S, et al. Hedgehog signaling regulates bladder cancer growth and tumorigenicity. Cancer Res. 2012;72(17):4449-58. doi:10.1158/ 0008-5472.CAN-11-4123.

40. Majid S, Saini S, Dahiya R. Wnt signaling pathways in urological cancers: past decades and still growing. Mol Cancer. 2012;11:7. doi:10.1186/1476-4598-11-7.
41. Singh MM, Manton CA, Bhat KP, Tsai WW, Aldape K, Barton $\mathrm{MC}$, et al. Inhibition of LSD1 sensitizes glioblastoma cells to histone deacetylase inhibitors. Neuro Oncol. 2011;13(8):894-903. doi: 10.1093/neuonc/nor049.

42. Bose P, Dai Y, Grant S. Histone deacetylase inhibitor (HDACI) mechanisms of action: emerging insights. Pharmacol Ther. 2014;143(3):323-36. doi:10.1016/j.pharmthera.2014.04.004.

43. Frew AJ, Johnstone RW, Bolden JE. Enhancing the apoptotic and therapeutic effects of HDAC inhibitors. Cancer Lett. 2009;280(2): 125-33. doi:10.1016/j.canlet.2009.02.042.

44. Falkenberg KJ, Johnstone RW. Histone deacetylases and their inhibitors in cancer, neurological diseases and immune disorders. Nat Rev Drug Discov. 2014;13(9):673-91. doi:10.1038/nrd4360.

45. Lai F, Guo ST, Jin L, Jiang CC, Wang CY, Croft A, et al. Cotargeting histone deacetylases and oncogenic BRAF synergistically kills human melanoma cells by necrosis independently of RIPK1 and RIPK3. Cell Death Dis. 2013;4:e655. doi:10.1038/ cddis.2013.192.

46. Florl AR, Schulz WA. Chromosomal instability in bladder cancer. Arch Toxicol. 2008;82(3):173-82. doi:10.1007/s00204-008-02803.

47. Zhijun H, Shusheng W, Han M, Jianping L, Li-Sen Q, Dechun L. Pre-clinical characterization of 4SC-202, a novel class I HDAC inhibitor, against colorectal cancer cells. Tumour Biol. 2016. doi: 10.1007/s13277-016-4868-6.

48. Fu M, Wan F, Li Z, Zhang F. 4SC-202 activates ASK1-dependent mitochondrial apoptosis pathway to inhibit hepatocellular carcinoma cells. Biochem Biophys Res Commun. 2016;471(2):267-73. doi:10.1016/j.bbrc.2016.01.030.

49. Valls E, Sanchez-Molina S, Martinez-Balbas MA. Role of histone modifications in marking and activating genes through mitosis. J Biol Chem. 2005;280(52):42592-600. doi:10.1074/jbc. M507407200.

50. Chuang C, Lin SH, Huang F, Pan J, Josic D, Yu-Lee LY. Acetylation of RNA processing proteins and cell cycle proteins in mitosis. J Proteome Res. 2010;9(9):4554-64. doi:10.1021/ pr100281h.

51. Kuffer C, Kuznetsova AY, Storchova Z. Abnormal mitosis triggers p53-dependent cell cycle arrest in human tetraploid cells. Chromosoma. 2013;122(4):305-18. doi:10.1007/s00412-0130414-0.

52. Knowles MA, Hurst CD. Molecular biology of bladder cancer: new insights into pathogenesis and clinical diversity. Nat Rev Cancer. 2015;15(1):25-41. doi:10.1038/nrc3817.

53. Earl J, Rico D, Carrillo-de-Santa-Pau E, Rodriguez-Santiago B, Mendez-Pertuz M, Auer H, et al. The UBC-40 urothelial bladder cancer cell line index: a genomic resource for functional studies. BMC Genomics. 2015;16:403. doi:10.1186/ s12864-015-1450-3. 